\title{
LA IMAGEN DE LA LAGARTIJA EN LA ICONOGRAFÍA PREHISPÁNICA DEL NOROESTE ARGENTINO II: ANÁLISIS DE REPRESENTACIONES
}

\author{
LIZARD IMAGES DEPICTED IN PREHISPANIC ICONOGRAPHY OF \\ NORTHWEST ARGENTINA II: ANALYSIS OF REPRESENTATIONS
}

Débora M. Kligmanna \& María Pía Falchib

El análisis de la iconografía prehispánica del Noroeste Argentino (NOA) ha estado centrado en las figuras de camélidos, felinos, serpentiformes y antropomorfos. El presente trabajo analiza la lagartija, un animal muy poco estudiado. El objetivo es identificar patrones en su modo de representación a lo largo del tiempo para contribuir a la comprensión del universo simbólico de las sociedades del pasado en dicha región, así como las relaciones entre el hombre y la fauna de su entorno. Para ello se analizaron tanto imágenes de lagartijas publicadas en la literatura arqueológica argentina como piezas seleccionadas del Museo Nacional del Hombre y del Museo Etnográfico J. B. Ambrosetti.

Palabras clave: Lagartijas, Iconografía, Análisis tipológico, Patrones de representación, Noroeste Argentino.

The analysis of the pre-Hispanic iconography of the Argentine Northwest (ANW) has focused on camelid, feline, serpent-shaped and anthropomorphic figures. The present study, instead, analyzes an understudied animal so far: the lizard. The aim is to identify patterns in the way it is represented over time in order to broaden our understanding of the symbolic universe of past so cieties in this region and of the relations between humans and their surrounding fauna. To this end, images of lizards published in the Argentinian archaeological literature were analyzed along with selected pieces from the National Museum of Man and from the J. B. Ambrosetti Ethnographic Museum.

Keywords: Lizards, Iconography, Typological analysis, Representation patterns, Argentine Northwest.

\section{INTRODUCCIÓN}

El análisis que aquí se presenta se inserta en un proyecto de mayor alcance, cuyo objetivo general es identificar cambios en el modo de representación de los reptiles (lagartijas y serpentiformes) a lo largo del tiempo en el Noroeste Argentino (NOA) (Kligmann \& Díaz País 2007). Esto permitirá comprender las características morfológicas de las representaciones de los distintos tipos de reptiles para luego señalar semejanzas y diferencias entre ellas.

Los reptiles son muy frecuentes en la iconografía prehispánica del NOA (Kligmann \& Díaz País 2007). Su representación se registra desde el Período Agroalfarero Temprano o Formativo (PF, 500 AC-650 DC), continúa en los Períodos Medio o de Integración Regional (PIR, 650-850 DC) y Tardío o de Desarrollos Regionales (PDR, 850-1480 DC), disminuyendo en el Período Inca (PI, 1480-1540 DC) (González \& Pérez 2000). Actualmente, esta propuesta clásica de periodificación está siendo discutida ya que sitios excavados en las últimas décadas, asignados a algunos de estos períodos, así como la recalibración de fechados radiocarbónicos previos, arrojaron resultados que no se corresponden con

A Débora M. Kligmann, CONICET - Instituto de Arqueología, Facultad de Filosofía y Letras, Universidad de Buenos Aires. 25 de Mayo $217-3^{\text {er }}$ piso, C1002ABE CABA. E-mail: kligmann@gmail.com

B María Pía Falchi, Instituto Nacional de Antropología y Pensamiento Latinoamericano. Secretaría de Gobierno de Cultura de la Nación. 3 de febrero 1370, C1426BJN cABA. E-mail: mpiafalchi@gmail.com 
este rígido esquema (Callegari 2004, Gordillo 2007, Korstanje et al. 2015).

Ahora bien, a pesar de la gran cantidad de reptiles registrados en la iconografía, los hallazgos de restos óseos y dentarios de estos animales en sitios arqueológicos de la Argentina son escasos. De los 25 casos conocidos solo cinco provienen del NOA. Dentro de estos últimos, dos de ellos corresponden a grandes acumulaciones (más de 1700 especímenes) de pequeños reptiles y ambos conjuntos fueron recuperados en sitios de esta región: lagartijas (Albino \& Kligmann 2007; Kligmann 2009, 2015; Kligmann et al. 1999) y anfisbenas (Albino \& Kligmann 2009, Kligmann 2015, Kligmann \& Albino 2007, Kligmann et al. 2013). En los 23 casos restantes se recuperaron unos pocos individuos aislados, identificados como lagartos, serpientes y tortugas (Kligmann 2009, 2015; Kligmann \& Díaz País 2007; Kligmann et al. 2013).

El presente trabajo busca analizar la representación de un animal muy poco estudiado en la iconografía del NOA, cuyo análisis ha estado centrado principalmente en las figuras de camélidos, felinos, serpentiformes y antropomorfos (Aschero 2000; Balesta 2015; de Hoyos 2013; González 1998; Gordillo 1998, 2009; Gordillo et al. 2000; Kligmann \& Díaz País 2007; Kusch 1991; Palamarczuk et al. 2015; Puente \& Quiroga 2006; Reynoso \& Pratolongo 2008; Sempé \& Baldini 2002, 2004; Vilas 2016, entre otros). El objetivo es, a partir de una tipología elaborada previamente (Kligmann \& Falchi 2018), identificar patrones en el modo de representación de las lagartijas. De esta manera se podrá discutir el lugar que ocuparon las lagartijas en la iconografía prehispánica del NOA, especialmente de la región valliserrana, teniendo en cuenta los diferentes períodos mencionados. Se trata de un análisis general de grano grueso, que busca comprender las particularidades en el modo de representación de estos animales más allá del estilo, las técnicas y/o los soportes. Así, este análisis permitirá reflexionar acerca del universo simbólico de las sociedades del pasado en dicha región, así como sobre las relaciones entre el hombre y la fauna de su entorno.

El término "lagartija" no es un término biológico sino un nombre común que comprende un grupo de saurios diversos de características variadas, en general pequeños, a diferencia de los lagartos (Albino com. pers.). No obstante, en las representaciones analizadas en este trabajo, ambos -lagartos y lagartijas- pueden confundirse, teniendo en cuenta que no brindan información sobre el tamaño real de los animales (Kligmann \& Falchi 2018).

\section{DEFINIENDO EL UNIVERSO A ANALIZAR}

El orden Squamata (reptiles cuyos cuerpos están cubiertos de escamas) incluye lacertilios o saurios (lagartijas, lagartos, iguanas, camaleones y geckos, entre otros), serpientes y anfisbenas (Garin \& Hussein 2013, Palermo 1984b).

Tanto lagartija como lagarto son términos amplios, pero por lo general se interpreta que un lagarto es más grande que una lagartija y que dentro de los lagartos puede haber formas sin patas o con patas reducidas, mientras que las lagartijas siempre tienen cuatro patas. Asimismo, dentro de este universo, la biología distingue categorías que no se definen solamente por el tamaño del saurio sino por otras características más o menos perceptibles (Albino com. pers.), que incluyen desde el estudio cromosómico hasta el de su estructura ósea (Palermo 1984a).

Así, lagartos y lagartijas constituyen un grupo muy variado y heterogéneo, con diferencias que abarcan desde sus hábitos alimenticios hasta los hábitats donde viven. También se observan diferencias en sus dimensiones, la coloración de sus cuerpos, el tamaño, forma y disposición de las escamas que los recubren, sus formas de reproducción, la cantidad de individuos por parición y las formas de las partes de sus cuerpos (Garin \& Hussein 2013, Palermo 1984a).

Si bien son poco frecuentes, existen lagartijas bicéfalas debido a una anomalía genética que produce individuos que comparten partes de sus cuerpos. Las víboras con una cabeza en cada extremo del cuerpo, tal como se ilustran en el arte precolombino, no existen en la naturaleza. Excepcionalmente, algunas víboras nacen con dos cabezas ubicadas una al lado de la otra en un mismo extremo del cuerpo (Kligmann et al. 2013). En el caso de las lagartijas, ambas cabezas pueden estar una al lado de la otra o bien una en cada extremo del cuerpo, al igual que sucede con las tortugas. Así, las representaciones bicéfalas podrían estar reflejando dichas anomalías o bien ser interpretaciones de la realidad de seres reales o míticos, con o sin connotaciones simbólicas (Kligmann \& Falchi 2018).

A pesar de la heterogeneidad recién mencionada, en la naturaleza todas las lagartijas comparten ciertos atributos básicos: 1) cabeza triangular o terminada en punta, 2) cuerpo alargado, 3) cuatro patas desarrolladas en forma perpendicular al cuerpo, 4) cinco dedos en cada pata y 5) cola larga (más larga que las patas traseras) 
(Kligmann \& Falchi 2018). Si bien no existen límites a la hora de representar la realidad, que no necesariamente se plasma tal cual es, estas características pueden o no registrarse en las representaciones de estos animales.

En función de todo lo antedicho, para la tipología propuesta se decidió que las representaciones de lagartijas, para ser consideradas como tales, debían cumplir con al menos tres de las cinco características básicas anteriormente mencionadas.

\section{METODOLOGÍA}

En un trabajo anterior (Kligmann \& Falchi 2018) se elaboró una propuesta tipológica para el análisis de las representaciones de lagartijas, siguiendo criterios definidos previamente (Falchi \& Podestá 2015; Falchi et al. 2011, 2013; Kligmann \& Díaz País 2007).

El trabajo de elaboración de la mencionada tipología constó de dos etapas. La primera consistió en la recopilación y digitalización (escaneado y calcado) de imágenes de lagartijas presentes en la iconografía prehispánica del NOA, dominando aquellas de la región valliserrana. En la segunda etapa se describieron dichas imágenes a fin de proponer una tipología.

La tipología fue el resultado de un largo proceso de retroalimentación entre la unidad de análisis seleccionada (cada motivo) y los atributos de las variables consideradas, enfrentando el desafío de dar cuenta de todos los tipos registrados. A partir de la variabilidad observada en el conjunto considerado, se ordenó la información recabada y, de esta manera, se generó una herramienta metodológica de análisis (Kligmann \& Falchi 2018).

Para este trabajo se analizó cada uno de los motivos de lagartijas registrados en el banco de imágenes utilizado para la elaboración de la tipología recién mencionada, lo que permitió relevar patrones en su modo de representación sobre la base de los tipos ya establecidos (Kligmann \& Falchi 2018). Esto hizo posible la identificación de tendencias generales para toda la muestra, así como tendencias particulares para cada uno de los períodos considerados, que son presentadas en esta oportunidad.

\section{Materiales}

El banco de datos utilizado está compuesto por imágenes publicadas en la literatura arqueológica argentina, así como por motivos representados en tres piezas cerámicas -depositadas en el Museo Nacional del Hombre del Instituto Nacional de Antropología y Pensamiento Latinoamericano (INAPL) - y en una de metal del Museo Etnográfico Juan Bautista Ambrosetti (FFyL, UBA).

Cabe aclarar que en el caso de las figuras publicadas se consideraron las imágenes que para nosotras representaban lagartijas, independientemente de la adscripción faunística otorgada por los autores de los trabajos consultados. Asimismo, se asumió que dichas imágenes (tanto fotografías como dibujos) constituían reproducciones confiables de los materiales originales (Kligmann \& Falchi 2018).

Si bien la búsqueda fue minuciosa, se considera que las 62 imágenes recopiladas representan solo algunos ejemplos de un conjunto mucho mayor. Hay varias figuras publicadas que seguramente quedaron fuera del alcance de esta investigación y, a su vez, hay muchas que aún se encuentran inéditas. En consecuencia, esta propuesta es una primera aproximación a la problemática planteada y las tendencias observadas deberán testearse incorporando más bibliografía, así como materiales de colecciones aún no publicados (Kligmann \& Falchi 2018).

Cuando las imágenes originales presentaban más de una representación de lagartija, cada una fue considerada por separado (recurriendo a las letras para los motivos $-a, b, c$, d, etc.- pero conservando el mismo número de figura general). Por esta razón, algunas de las figuras originales se subdividieron en unidades menores para el análisis, dando un total de 119 representaciones (tabla 1).

Para los cuatro casos de lagartijas bicéfalas presentes en el conjunto analizado (dos del PIR y dos del PDR), se describió cada cabeza por separado para registrar eventuales diferencias entre ellas, pero considerando el motivo como una unidad. Por esta razón, el número total de cabezas de la muestra relevada asciende a 123.

De las 119 representaciones relevadas, seis no pudieron ser asignadas cronológicamente debido a que la publicación de la cual provienen no especifica su temporalidad. Además, al ser diferentes de los motivos restantes, tampoco pudieron ser asignadas por comparación estilística a un período en particular. No obstante, se decidió incluirlas en el banco de datos recopilado dado que interesaba aumentar la variabilidad de la muestra a ser analizada.

El hecho de recurrir mayormente a imágenes publicadas $y$, en menor medida, a las piezas originales en sí mismas tiene sus limitaciones. Por ejemplo, se 
Tabla 1. Cuantificación de las representaciones de lagartijas del banco de datos, desglosadas por período y soporte. Table 1. Quantification of the representations of lizards from the data base, disaggregated by period and support.

\begin{tabular}{|c|c|c|c|c|c|c|c|c|}
\hline \multirow{3}{*}{\multicolumn{2}{|c|}{ PERÍODO }} & \multicolumn{7}{|c|}{ SOPORTE } \\
\hline & & \multirow[t]{2}{*}{ CERÁMICA } & \multicolumn{2}{|c|}{ ROCA } & \multirow[t]{2}{*}{ METAL } & \multirow[t]{2}{*}{ HUESO } & \multicolumn{2}{|c|}{ TOTAL } \\
\hline & & & ARTE RUPESTRE & ARTE MOBILIAR & & & $\mathrm{N}^{\circ}$ & $\%$ \\
\hline \multicolumn{2}{|c|}{ Formativo } & 12 & 1 & 1 & 0 & 0 & 14 & 11,76 \\
\hline \multicolumn{2}{|c|}{ Integración Regional } & 36 & 15 & 0 & 0 & 1 & 52 & 43,70 \\
\hline \multicolumn{2}{|c|}{ Desarrollos Regionales } & 25 & 6 & 0 & 16 & 0 & 47 & 39,50 \\
\hline \multicolumn{2}{|c|}{ No asignado } & 6 & 0 & 0 & 0 & 0 & 6 & 5,04 \\
\hline \multirow{2}{*}{ Total } & No & 79 & 22 & 1 & 16 & 1 & 119 & 100 \\
\hline & $\%$ & 66,39 & 18,49 & 0,84 & 13,44 & 0,84 & 100 & \\
\hline
\end{tabular}

desconoce la posición de la imagen en la pieza real, su tamaño, o con qué otras representaciones se encuentra asociada (Kligmann \& Falchi 2018).

\section{Métodos}

Primero se elaboró una base de datos con información general de las figuras consideradas (por ejemplo, período y soporte) para luego analizar detalladamente cada representación en particular.

Para el análisis propiamente dicho se tomaron en cuenta las siguientes variables (Kligmann \& Falchi 2018):

1) Características generales: Vista y Tipo de Unión (entre cabeza y cuerpo, entre cuerpo y patas y entre cuerpo y cola).

2) Características de las cabezas: Contorno + Forma, Atributos, Tipo de tratamiento y Diseños internos.

3) Características de los cuerpos: Contorno + Forma, Tipo de tratamiento y Diseños internos.

4) Características de las patas: Posición + Orientación, Terminación (Dedos: Forma), Tipo de tratamiento y Diseños internos.

5) Características de las colas: Forma, Terminación, Tipo de tratamiento y Diseños internos.

Para la opción planta / perfil de la vista se consideraron dos alternativas:

1) cuerpo en planta y cabeza de perfil, con un solo ojo y boca.
2) cuerpo en planta y cabeza en planta, con dos ojos y boca (ya sea abierta o cerrada) que simula estar de perfil.

Para los atributos de la cabeza (ojos, boca, lengua, dientes y cuello) se registró su presencia o ausencia sin especificar el tipo o su descripción. Los atributos restantes se clasificaron de acuerdo con las opciones seleccionadas para cada una de las variables.

El tratamiento "Lineal" se aplica a las figuras definidas solo por la línea de contorno cerrada, que deja el fondo vacío, mientras que el tratamiento "Plano" se utiliza para figuras cuyas superficies totales tienen textura (Arnheim 1985). La categoría "Lineal/Plano" se emplea para representaciones que incluyan la combinación de ambas opciones en su diseño.

La categoría "Combinado" se utilizó para figuras que presentaban varias opciones individuales vinculadas en una misma representación (por ejemplo, motivos que incluyeran en sus diseños internos puntos y reticulado o dedos de distinto tipo en cada una de las patas). La opción "No corresponde" se empleó en el caso de figuras que no presentaran diseños internos, dedos o colas. La categoría "No determinado/a" se estableció para aquellos motivos que presentaran partes faltantes o poco claras por deterioro (Kligmann \& Falchi 2018).

Los resultados generales del análisis de las representaciones se presentan en las 10 tablas que conforman el cuerpo del presente trabajo, tomando en cuenta todos los 
tipos definidos previamente. El análisis pormenorizado de los resultados discriminados por período se comenta a continuación de los resultados generales, para cada una de las variables seleccionadas.

La información se ordenó por período. Sin embargo, el único ejemplo correspondiente al PI, plasmado en un plato pato, en otro soporte sería una representación típica del PDR por la combinación de sus atributos. Por este motivo, se decidió incluirlo en el grupo del PDR. Por otra parte, establecer una categoría conformada por un único caso distorsionaría la información cuantificada.

Cabe aclarar que para la realización de las figuras 1 a 5 se seleccionaron con fines ilustrativos solo algunos de los muchos motivos del banco de datos. Por este motivo, dichas figuras no intentan dar cuenta de la totalidad de la muestra analizada.

\section{RESULTADOS}

De todas las variables seleccionadas para analizar el modo de representación de las lagartijas, no todas muestran el mismo grado de variabilidad, teniendo en cuenta la cantidad de alternativas que exhibe cada una. Algunas, como la vista, solo presentan unas pocas opciones mientras que otras, como el diseño interno, aceptan muchas variantes.

Por otro lado, mientras que algunas de las representaciones combinan varias alternativas de una misma variable en las diferentes partes de su cuerpo, otras están ejecutadas de manera uniforme, recurriendo a una sola opción para todo el cuerpo (por ejemplo, en tipo de unión, tipo de tratamiento o diseños internos).

\section{Vista}

En lo que respecta a la vista se presentan cuatro alternativas. En el conjunto analizado domina por gran mayoría la opción en "Planta" (fig. 1, A1), seguida en mucho menor medida por la opción "Planta/Perfil B2" (cuerpo y cabeza en planta, con dos ojos y boca abierta de perfil) (fig. 1, C4 y fig. 2, B). Las alternativas "Planta/ Perfil B1" (cuerpo y cabeza en planta, con dos ojos y boca cerrada de perfil) (fig. 1, B1) y "Planta/Perfil A" (cuerpo en planta, cabeza de perfil con un solo ojo y boca) (fig. 3, B) están muy escasamente representadas (tabla 2). Esta última se identifica en casos de combinación con otros grupos animales.
Cabe destacar que la alternativa "Perfil" se encuentra ausente. Así, no se recurre a esta posibilidad para representar a las lagartijas en la muestra aquí considerada, tal como sucede con los ofidios y a diferencia de lo que ocurre con otros animales como el felino, que suele caracterizarse de perfil (Kligmann \& Díaz País 2007).

Si se analiza esta variable por período, se puede mencionar que todas las lagartijas del PF se representan en "Planta" mientras que las del PDR se encuentran tanto en "Planta" como en "Planta / Perfil B2". Esta última opción es exclusiva del PDR.

Las del PIR son las de mayor variabilidad, ya que presentan tres alternativas: en "Planta", "Planta / Perfil A" y "Planta / Perfil B1", aunque una de ellas es dominante (en "Planta"). Estas últimas dos opciones son exclusivas de este período.

\section{Tipo de tratamiento}

Se analizó el tipo de tratamiento para cada parte del cuerpo, habiendo en este caso tres alternativas (tabla 3 ).

En el total de la muestra analizada predomina el tipo de tratamiento "Lineal" para todas las partes del cuerpo (cabeza, cuerpo, patas y cola) (fig. 1, B3). Sigue en cantidad de casos el tratamiento "Plano" de las figuras (fig. 1, B4) y, por último, la combinación de ambos tipos (fig. 1, C1).

Para la cabeza se recurre a los tratamientos "Plano" o "Lineal" en porcentajes muy similares, estando la opción "Lineal / Plano" representada en mucho menor medida. Para el cuerpo y la cola sucede algo similar, aunque cambian los porcentajes. Aquí también domina la alternativa "Lineal", seguida de los tratamientos "Plano" y "Lineal/Plano". Para las patas se presenta la misma tendencia que para los cuerpos aunque las diferencias entre las categorías son más notorias.

Si consideramos cada parte del cuerpo por separado teniendo en cuenta los diferentes períodos de adscripción, se observa que en las cabezas predomina el tratamiento "Lineal" en los PF y PIR, mientras que en el PDR y en las representaciones no asignadas cronológicamente se destacan las de tratamiento "Plano".

En el caso de los cuerpos predomina el tratamiento "Lineal" en tres de los períodos, diferenciándose de los ejemplos que no pudieron ser asignados cronológicamente. Se ha observado la misma situación en las patas. Sin embargo, en el tratamiento de esta parte del cuerpo, el porcentaje de casos de tratamiento "Plano" es mayor en el PDR que en los períodos restantes. 

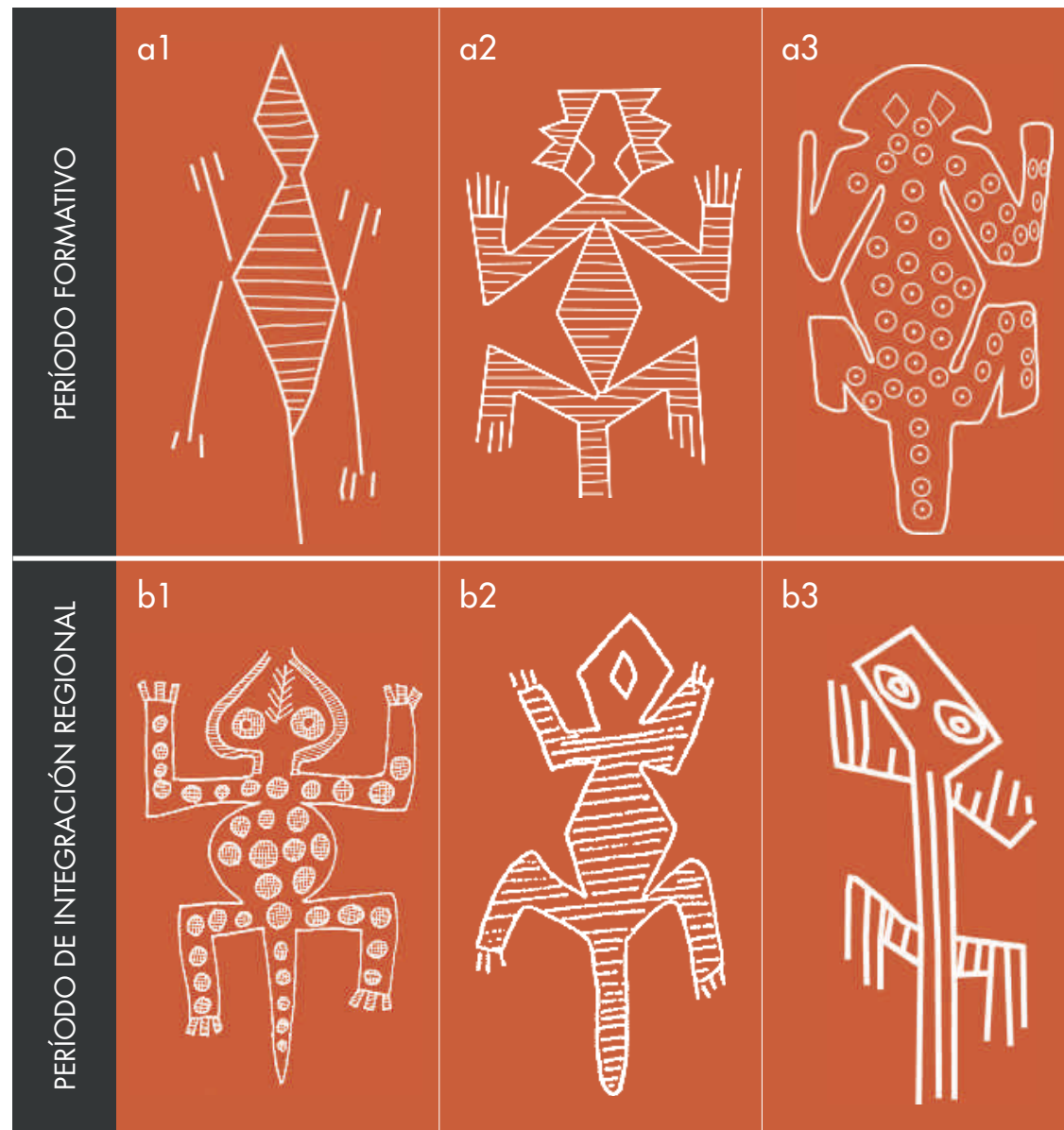

b4

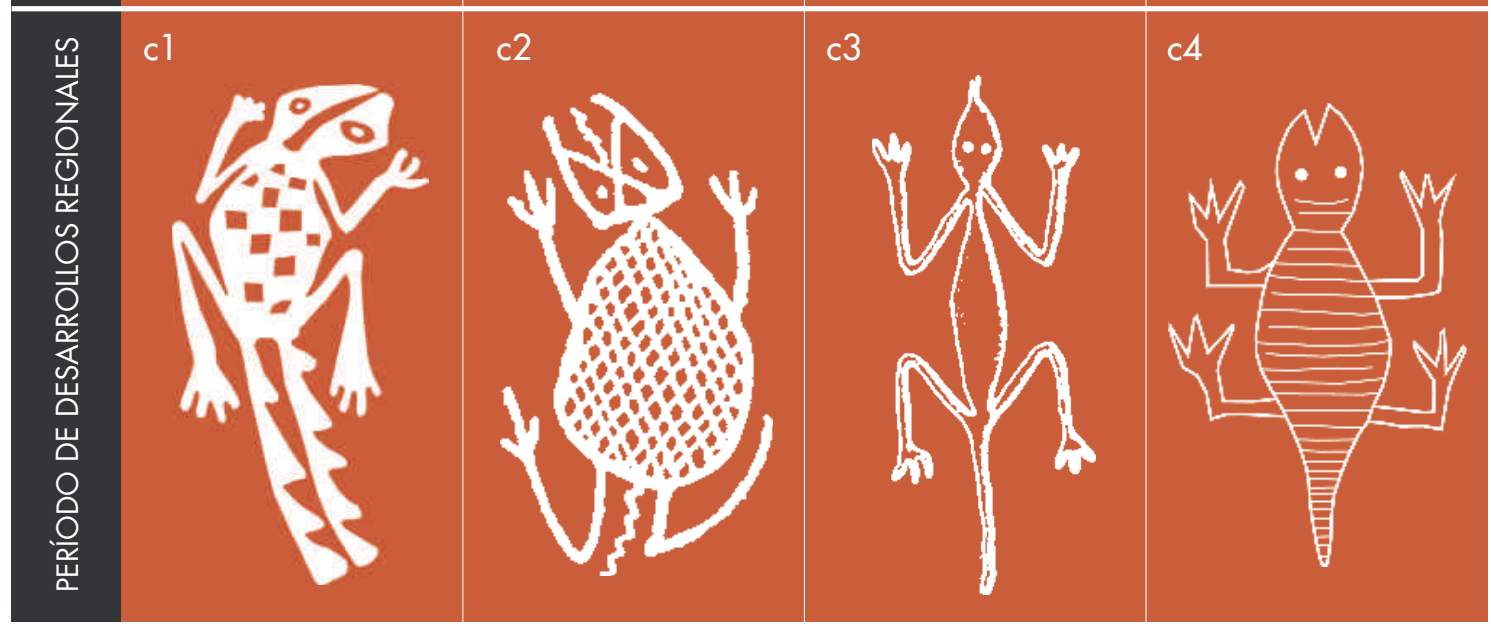

Figura 1. Ejemplos del modo de representación de las lagartijas en los distintos períodos considerados (las imágenes utilizadas fueron adaptadas de los siguientes textos y piezas: A1: Pieza 261, Museo Nacional del Hombre (INAPL); A2: Serrano 1966: 98; A3: González 1977: 270; B1: Bedano et al. 1993: 97; B2: Korstanje 1988: 315; B3: Goretti 2006: 230; B4: Ferraro 2005, anexo 9.2; C1: Goretti 2006: 201; C2: Ambrosetti 1899: 119; C3: González 1992: 353; C4: Goretti 2007: 152). Figure 1. Examples of the different types of representation of lizards in the analyzed periods (the images were adapted from the following texts and pieces: A1: Piece 261, National Museum of Man (INAPL); A2: Serrano 1966: 98; A3: González 1977: 270; B1: Bedano et al. 1993: 97; B2: Korstanje 1988: 315; B3: Goretti 2006: 230; B4: Ferraro 2005, annex 9.2; C1: Goretti 2006: 201; C2: Ambrosetti 1899: 119; C3: González 1992: 353; C4: Goretti 2007: 152). 


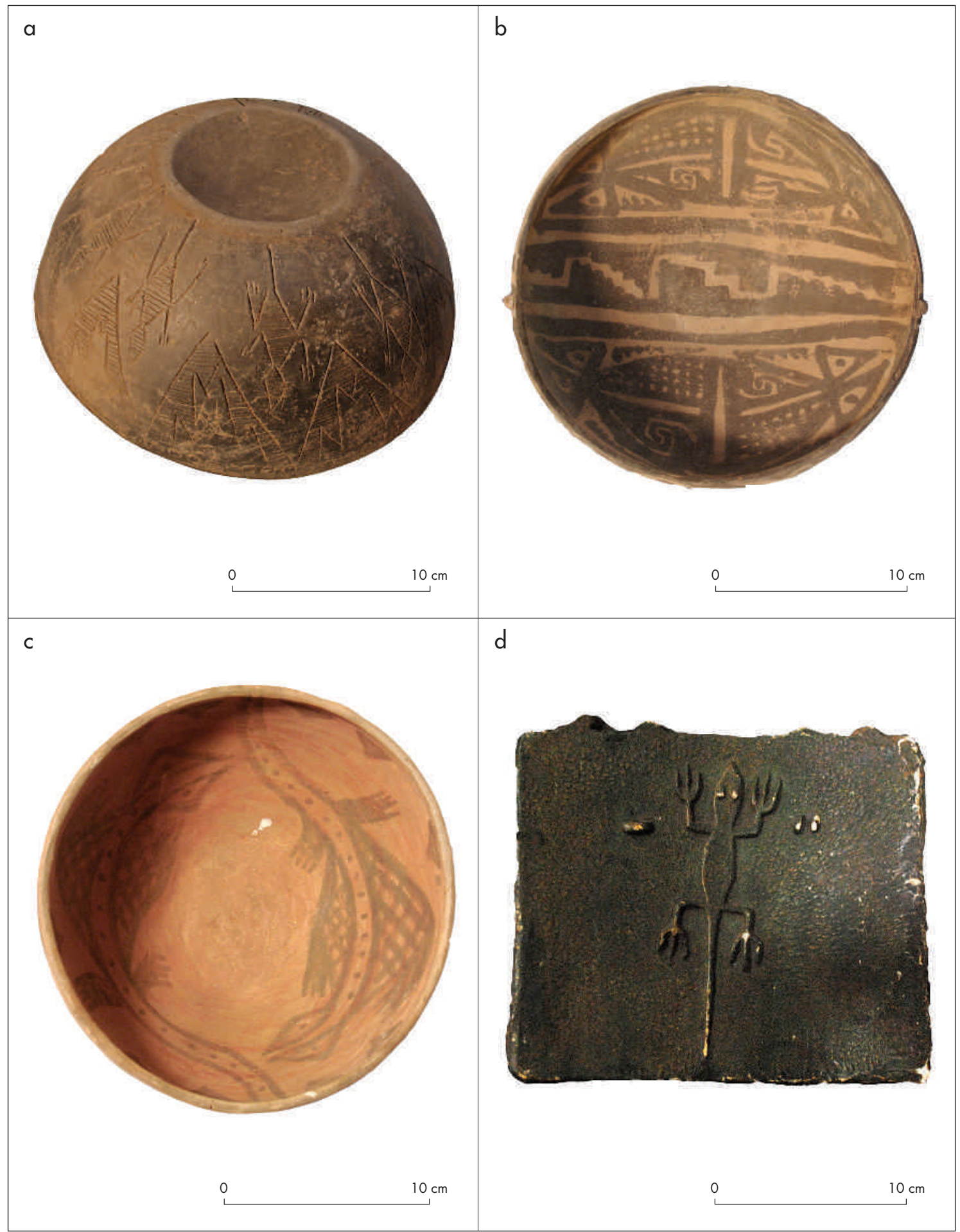

Figura 2. Ejemplos de piezas cerámicas (número 261, 358 y 586, Museo del Hombre, INAPL) y de metal (número 28194, Museo Etnográfico Juan Bautista Ambrosetti, FFyL, UBA) con representaciones de lagartijas. Figure 2. Examples of pieces of pottery (number 261,358 and 586, Museum of Man, INAPL) and metal piece (number 28194, Ethnographic Museum Juan Bautista Ambrosetti, Faculty of Philosophy and Letters, University of Buenos Aires) with images of lizards. 


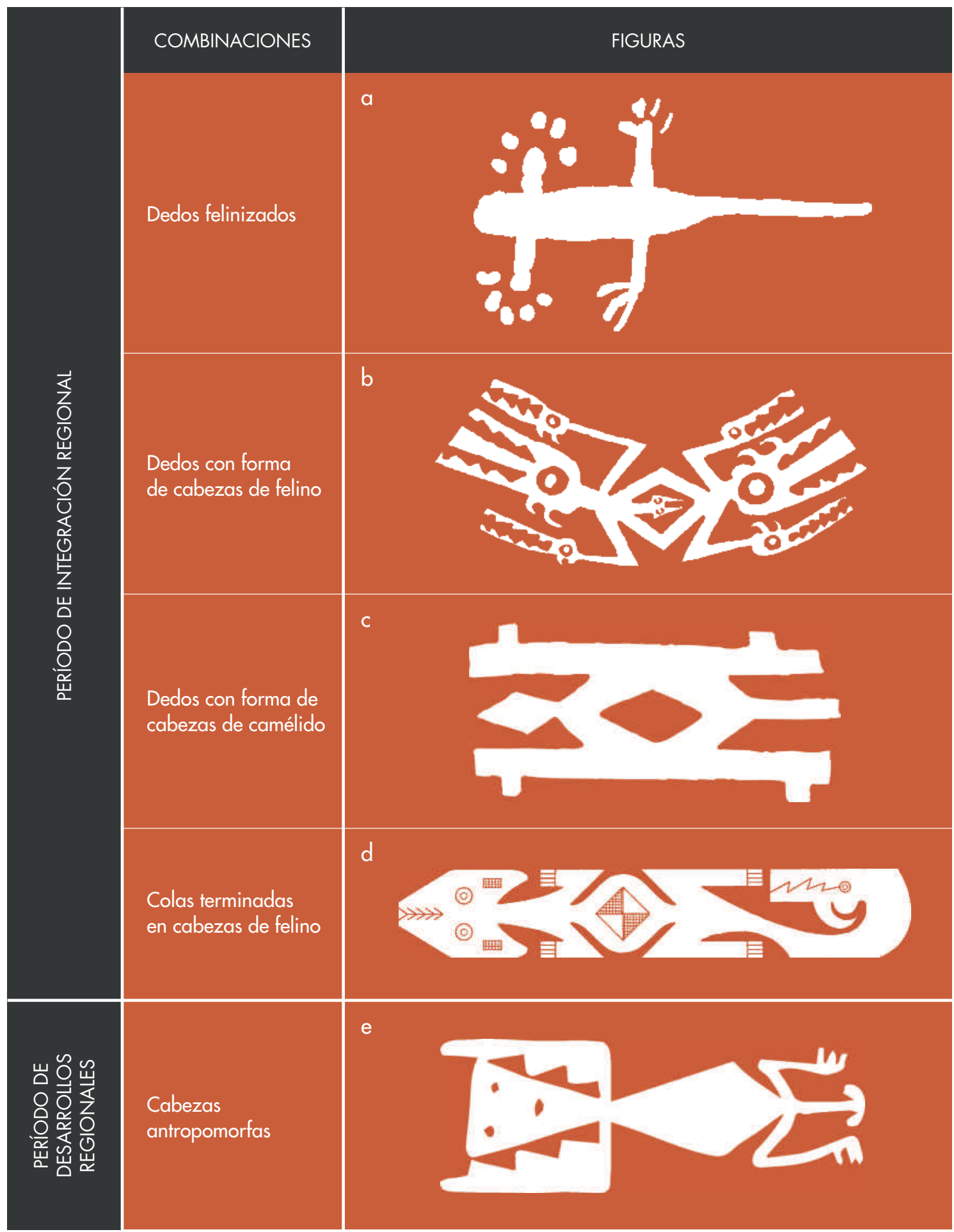

Figura 3. Ejemplos de combinaciones de lagartijas con otros grupos animales del PIR y del PDR (las imágenes utilizadas fueron adaptadas de los siguientes textos: A: Falchi et al. 2011: 45; B: Lafone Quevedo 1908: 373; C: Sempé 1998: 277; D: Fiadone 2001: 108; E: Basile 2005: 130). Figure 3. Examples of the combinations of lizards with other animal groups from the RIP and the RDP (the images used were adapted from the following texts A: Falchi et al. 2011: 45; B: Lafone Quevedo 1908: 373; C: Sempé 1998: 277; D: Fiadone 2001: 108; E: Basile 2005: 130). 
Tabla 2. Vista, discriminada por período. Table 2. View, per period.

\begin{tabular}{|c|c|c|c|c|c|c|c|c|c|c|}
\hline \multirow[b]{3}{*}{ VISTA } & \multicolumn{10}{|c|}{ PERÍODO } \\
\hline & \multicolumn{2}{|c|}{ FORMATIVO } & \multicolumn{2}{|c|}{$\begin{array}{l}\text { INTEGRACIÓN } \\
\text { REGIONAL }\end{array}$} & \multicolumn{2}{|c|}{$\begin{array}{l}\text { DESAROLLOS } \\
\text { REGIONALES }\end{array}$} & \multicolumn{2}{|c|}{ NO ASIGNADO } & \multicolumn{2}{|c|}{ TOTAL } \\
\hline & $\mathrm{N}^{\circ}$ & $\%$ & $\mathrm{~N}^{\circ}$ & $\%$ & $\mathrm{~N}^{\circ}$ & $\%$ & No & $\%$ & $\mathrm{~N}^{\circ}$ & $\%$ \\
\hline Planta & 14 & 100 & 47 & 90,38 & 26 & 55,32 & 6 & 100 & 93 & 78,15 \\
\hline Planta / Perfil A & 0 & 0,00 & 2 & 3,85 & 0 & 0,00 & 0 & 0,00 & 2 & 1,68 \\
\hline Planta / Perfil B1 & 0 & 0,00 & 3 & 5,77 & 0 & 0,00 & 0 & 0,00 & 3 & 2,52 \\
\hline Planta / Perfil B2 & 0 & 0,00 & 0 & 0,00 & 21 & 44,68 & 0 & 0,00 & 21 & 17,65 \\
\hline TOTAL & 14 & 100 & 52 & 100 & 47 & 100 & 6 & 100 & 119 & 100 \\
\hline
\end{tabular}

Tabla 3. Tipo de tratamiento, por partes del cuerpo. Table 3. Types of treatment, body parts.

\begin{tabular}{|c|c|c|c|c|c|c|c|c|}
\hline \multirow{3}{*}{$\begin{array}{l}\text { TIPO DE } \\
\text { TRATAMIENTO }\end{array}$} & \multicolumn{8}{|c|}{ PARTES DEL CUERPO } \\
\hline & \multicolumn{2}{|c|}{ CABEZA } & \multicolumn{2}{|c|}{ CUERPO } & \multicolumn{2}{|c|}{ PATAS } & \multicolumn{2}{|c|}{ COLA } \\
\hline & $\mathrm{N}^{0}$ & $\%$ & $\mathrm{~N}^{\circ}$ & $\%$ & $\mathrm{~N}^{\circ}$ & $\%$ & $\mathrm{~N}^{\circ}$ & $\%$ \\
\hline Lineal & 59 & 47,97 & 61 & 51,26 & 72 & 47,97 & 68 & 47,97 \\
\hline Plano & 54 & 43,90 & 38 & 31,93 & 38 & 43,90 & 32 & 43,90 \\
\hline Lineal / Plano & 8 & 6,50 & 20 & 16,81 & 9 & 6,50 & 10 & 6,50 \\
\hline No corresponde & 0 & 0,00 & 0 & 0,00 & 0 & 0,00 & 8 & 0,00 \\
\hline No determinado & 2 & 1,63 & 0 & 0,00 & 0 & 1,63 & 1 & 1,63 \\
\hline TOTAL & 123 & 100 & 119 & 100 & 119 & 100 & 119 & 100 \\
\hline
\end{tabular}

Para el tratamiento de las colas, en todos los períodos predomina el tratamiento "Lineal" sobre el "Plano" mientras que los casos no asignados son en su totalidad de tratamiento "Plano".

\section{Contorno y forma de las cabezas}

A partir de la combinación de dos variables (contorno y forma) surgen 12 opciones posibles para las cabezas. La forma más abundante es la "Romboidal simple" de contorno "Recto" (fig. 1, A1), seguida por la "Ovalada" de contorno "Curvo" (fig. 1, C4). También se destaca la forma "Irregular" de contorno "Curvo/Recto" (fig. 1, B1), la "Circular simple" de contorno "Curvo" y la "Triangular doble, con triángulos opuestos por la base" de contorno "Recto" (fig. 1, C1) (tabla 4).

Si se considera la distribución por período se observa que para el PF predominan las cabezas de forma "Romboidal simple", con casos minoritarios de forma "Ovalada", "Semicircular" (fig. 1, A3) e "Irregular" (fig. 1, A2). Del mismo modo, en el PIR predominan las cabezas de forma "Romboidal simple", "Irregular" y "Circular simple". 
Tabla 4. Contorno y forma de las cabezas, discriminados por período. Table 4. Outline and shape of the heads, perperiod.

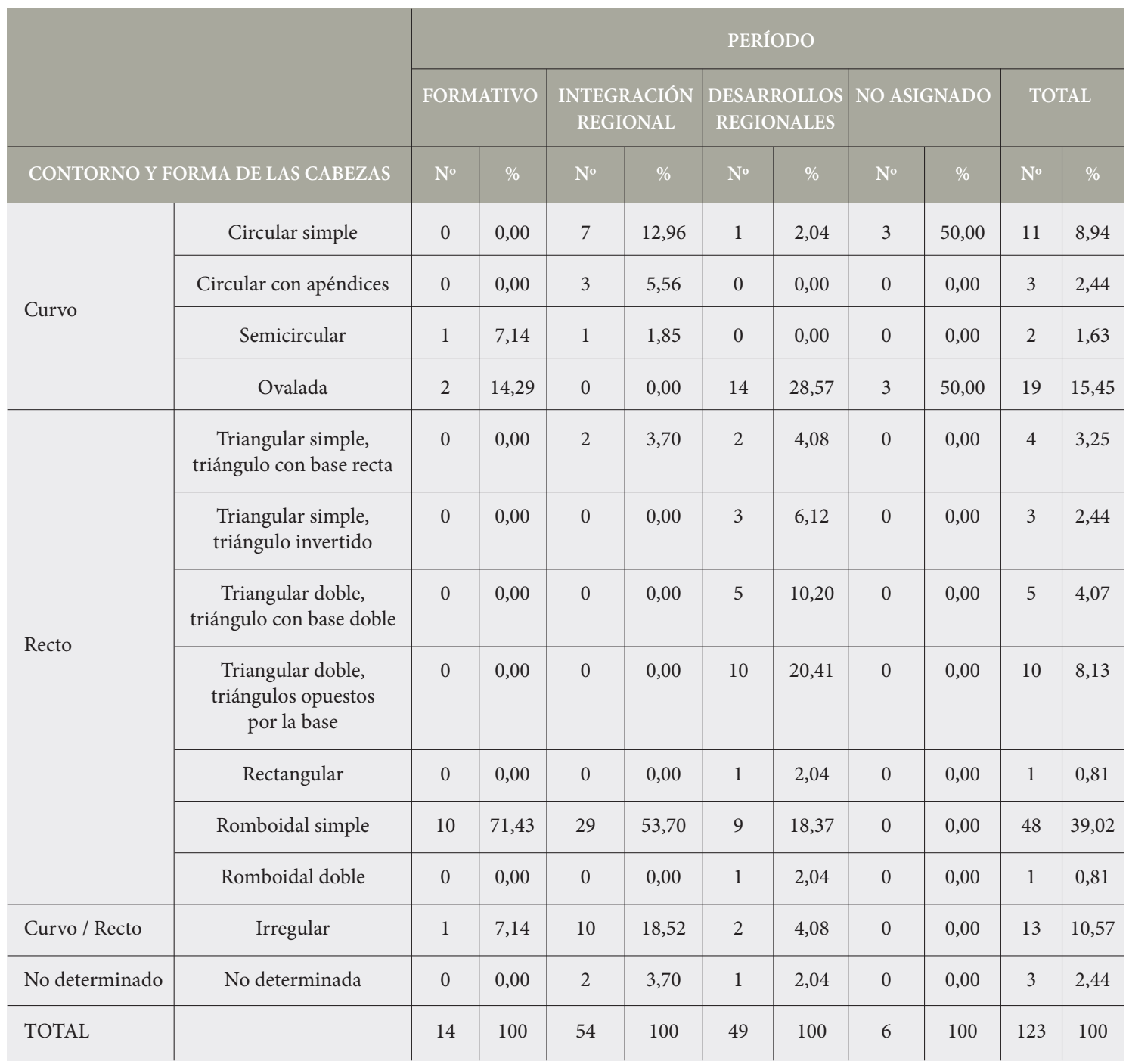

Para el PDR se observa una notable variabilidad en la forma de las cabezas que no es apreciable en los dos períodos anteriores (fig. 1, C1, C2, C3 y C4). Excepto las formas "Circular con apéndices" (fig. 1, B4) y "Semicircular", todas las demás opciones están presentes. La forma con mayor cantidad de ejemplos es la "Ovalada", seguida de la "Romboidal Simple", la "Triangular doble, con triángulos opuestos por la base" y la "Triangular doble, con base doble". En cuanto a las figuras cuyo período no ha podido determinarse se presentan las formas "Circular simple" y "Ovalada".

\section{Atributos de las cabezas}

En todos los ejemplos analizados, los casos de ausencia de ojos, boca, lengua, dientes y cuello son más elevados que los de presencia, aunque no siempre se registran en los mismos porcentajes. En consecuencia, estos atributos no son determinantes al momento de representar una lagartija (tabla 5) ni diagnósticos para identificarla como tal (fig. 1, A1 y B4). De hecho, la mayoría de los casos analizados no los presentan $\mathrm{y}$ de todas maneras pueden ser identificados como 
Tabla 5. Atributos de las cabezas. Table 5. Features of the heads.

\begin{tabular}{|c|c|c|c|c|c|c|c|c|}
\hline \multirow{2}{*}{$\begin{array}{l}\text { ATRIBUTOS } \\
\text { DE LAS CABEZAS }\end{array}$} & \multicolumn{2}{|c|}{ PRESENCIA } & \multicolumn{2}{|c|}{ AUSENCIA } & \multicolumn{2}{|c|}{ NO DETERMINADO } & \multicolumn{2}{|c|}{ TOTAL } \\
\hline & $\mathrm{N}^{\circ}$ & $\%$ & $\mathrm{~N}^{\circ}$ & $\%$ & $\mathrm{~N}^{\circ}$ & $\%$ & $\mathbf{N}^{\circ}$ & $\%$ \\
\hline Ojos & 51 & 41,46 & 71 & 57,72 & 1 & 0,81 & 123 & 100 \\
\hline Boca & 31 & 25,20 & 90 & 73,17 & 2 & 1,63 & 123 & 100 \\
\hline Lengua & 6 & 4,88 & 115 & 93,50 & 2 & 1,63 & 123 & 100 \\
\hline Dientes & 4 & 3,25 & 117 & 95,12 & 2 & 1,63 & 123 & 100 \\
\hline Cuello & 33 & 26,83 & 89 & 72,36 & 1 & 0,81 & 123 & 100 \\
\hline
\end{tabular}

lagartijas. La muestra analizada incluye dos casos no determinados por deterioro.

Cuando están presentes, los atributos más abundantes son los ojos (fig. 1, C1, C2, C3 y C4) seguidos de cuellos y bocas, siendo lenguas y dientes muy poco significativos. De los 51 casos con presencia de ojos, 17 están solos, sin combinar con otros atributos. De los 31 casos de bocas, 17 están combinados con ojos. Así, no siempre que hay ojos hay bocas pero siempre que hay bocas hay ojos.

En la muestra analizada solo se hallaron dos motivos que combinan todos los atributos de la cabeza. Se trata de ejemplos del PIR que corresponden a lagartijas bicéfalas, en donde un caso tiene estos cinco atributos combinados en ambas cabezas y el otro en una sola de las cabezas, estando ausente el cuello (fig. 5, A1 y B1). Respecto de los 33 cuellos representados, 11 están combinados con ojos y boca y dos solo con ojos.

Si se analiza la presencia de los atributos por período, se puede mencionar que las figuras del PF casi no presentan atributos, destacándose solo un caso con ojos y otro con cuello. De las figuras del PIR, la opción más representada es el cuello. Le siguen los ojos, las bocas, las lenguas y los dientes. Estos dos últimos solo están presentes en las dos lagartijas bicéfalas (fig. 5, A1 y B1).

En las figuras del PDR los ojos constituyen el atributo dominante. Le siguen las bocas y los cuellos. En este período solo hay dos casos con lengua mientras que los dientes no se utilizan (fig. 1, C2). Los seis casos no asignados carecen de atributos.

\section{Contorno y forma de los cuerpos}

$\mathrm{Al}$ igual que sucede con las cabezas, en el caso de los cuerpos hay distintas opciones que surgen de la combinación de contorno y forma. Sin embargo, la cantidad de combinaciones aquí es menor, con ocho en lugar de 12 (tabla 6).

También aquí domina la forma "Romboidal" de contorno "Recto" (fig. 1, A2) seguida por la "Ovalada" de contorno "Curvo" (fig. 1, C3). Se destaca a continuación la forma la "Irregular" de contorno "Curvo / Recto" y la "Rectangular" de contorno "Recto" (fig. 1, B3).

En los casos asignados al PF se registra una mayoría de forma "Romboidal" con casos aislados de forma "Rectangular", "Ovalada" e "Irregular". Para el PIR la mayoría de los casos son "Romboidales", seguidos por las formas "Ovalada", "Irregular" y "Circular". Esta última solo se identificó en este período.

En el PDR se destaca la forma "Ovalada" seguida de la "Romboidal" y la "Irregular". La forma "Almendrada", con pocos casos, es exclusiva de este período (fig. 1, C2). Para los ejemplos no asignados a ningún período solo se observó la forma "Rectangular".

\section{Forma de las patas}

La forma de las patas surge de la combinación de dos variables: posición y orientación, dando como resultado 10 alternativas diferentes (tabla 7). El tipo dominante, por notoria mayoría, es el de " 2 patas flexionadas hacia arriba y 2 patas flexionadas hacia abajo” (fig. 1, C3), seguido en menor medida por "4 patas flexionadas hacia arriba" (fig. 1, C4) y "2 patas extendidas hacia 
Tabla 6. Contorno y forma de los cuerpos, discriminados por período. Table 6. Outline and shape of the bodies, perperiod.

\begin{tabular}{|c|c|c|c|c|c|c|c|c|c|c|c|}
\hline & & \multicolumn{10}{|c|}{ PERIÍODO } \\
\hline & & \multicolumn{2}{|c|}{ FORMATIVO } & \multicolumn{2}{|c|}{$\begin{array}{l}\text { INTEGRACIÓN } \\
\text { REGIONAL }\end{array}$} & \multicolumn{2}{|c|}{$\begin{array}{l}\text { DESARROLLOS } \\
\text { REGIONALES }\end{array}$} & \multicolumn{2}{|c|}{ NO ASIGNADO } & \multicolumn{2}{|c|}{ TOTAL } \\
\hline \multicolumn{2}{|c|}{ CONTORNO Y FORMA DE LOS CUERPOS } & $\mathrm{N}^{\circ}$ & $\%$ & $\mathrm{~N}^{\circ}$ & $\%$ & $\mathrm{~N}^{\circ}$ & $\%$ & $\mathrm{~N}^{\circ}$ & $\%$ & $\mathrm{~N}^{\circ}$ & $\%$ \\
\hline \multirow{3}{*}{ Curvo } & Circular & 0 & 0,00 & 5 & 9,62 & 0 & 0,00 & 0 & 0,00 & 5 & 4,20 \\
\hline & Ovalada & 1 & 7,14 & 6 & 11,54 & 24 & 51,07 & 0 & 0,00 & 31 & 26,05 \\
\hline & Almendrada & 0 & 0,00 & 0 & 0,00 & 3 & 6,38 & 0 & 0,00 & 3 & 2,52 \\
\hline \multirow{4}{*}{ Recto } & Lineal & 0 & 0,00 & 3 & 5,77 & 2 & 4,25 & 0 & 0,00 & 5 & 4,20 \\
\hline & Rectangular & 1 & 7,14 & 2 & 3,85 & 3 & 6,38 & 6 & 100,00 & 12 & 10,08 \\
\hline & Romboidal & 11 & 78,57 & 29 & 55,77 & 9 & 19,16 & 0 & 0,00 & 49 & 41,18 \\
\hline & Irregular & 0 & 0,00 & 1 & 1,92 & 0 & 0,00 & 0 & 0,00 & 1 & 0,84 \\
\hline Curvo / Recto & Irregular & 1 & 7,14 & 6 & 11,54 & 6 & 12,76 & 0 & 0,00 & 13 & 10,92 \\
\hline TOTAL & & 14 & 100 & 52 & 100 & 47 & 100 & 6 & 100 & 119 & 100 \\
\hline
\end{tabular}

arriba y 2 patas extendidas hacia abajo, paralelas al cuerpo" (fig. 1, A1).

En el PF solo se registran casos con "2 patas extendidas hacia arriba y 2 patas extendidas hacia abajo, paralelas al cuerpo" y " 2 patas flexionadas hacia arriba y 2 patas flexionadas hacia abajo". En las representaciones del PIR se presentan seis opciones, dominando las mismas del período anterior, aunque en orden inverso.

Para el PDR también hay seis variantes, aunque dos de ellas son dominantes: "2 patas flexionadas hacia arriba y 2 patas flexionadas hacia abajo" y "4 patas flexionadas hacia arriba". Las opciones de " 2 patas flexionadas hacia arriba y 2 patas extendidas hacia arriba, paralelas al cuerpo" y de "4 patas adosadas al cuerpo", aunque escasamente representadas, son exclusivas de este período (fig. 1, C2 y fig. 2, C). Las representaciones no asignadas son todas de la misma modalidad: "4 patas flexionadas hacia arriba".

\section{Forma de los dedos}

Esta es una de las variables en donde se puede apreciar la combinación de rasgos de diferentes grupos animales, ya que aquí se recurre a atributos de felinos y camélidos como cabezas y pisadas.

Resulta llamativo que casi un 30\% de la muestra analizada no presenta dedos en las patas (fig. 1, B4). Cuando estos están presentes, la forma de los dedos exhibe siete opciones, dominando los dedos "Bifurcados" (fig. 1, C3). Le siguen los "Peiniformes con base" (fig. 1, A2), los "Peiniformes sin base" (fig. 1, A1) y los "Combinados" (tabla 8). Dentro de estos últimos, se observan las siguientes alternativas: a) dos de un tipo y dos de otro, b) tres de un mismo tipo y la cuarta diferente (fig. 1, C2) o c) dos de un tipo, una de otro y la restante presentando una tercera forma.

Los dedos en "Forma escalonada" no se presentan solos (misma opción en las 4 patas) sino combinados con otras formas como las "Peinformes con base". Lo mismo sucede con la opción de patas "Felinizadas", que nunca se encuentra sola en todas las patas sino combinada con otras formas como las "Bifurcadas". 
Tabla 7. Posición y orientación de las patas, discriminadas por período. Table 7. Position and orientation of the legs, per period.

\begin{tabular}{|c|c|c|c|c|c|c|c|c|c|c|c|}
\hline & & \multicolumn{10}{|c|}{ PERÍODO } \\
\hline & & \multicolumn{2}{|c|}{ FORMATIVO } & \multicolumn{2}{|c|}{$\begin{array}{l}\text { INTEGRACIÓN } \\
\text { REGIONAL }\end{array}$} & \multicolumn{2}{|c|}{$\begin{array}{l}\text { DESARROLLOS } \\
\text { REGIONALES }\end{array}$} & \multicolumn{2}{|c|}{ NO ASIGNADO } & \multicolumn{2}{|c|}{ TOTAL } \\
\hline \multicolumn{2}{|c|}{ POSICIÓN Y ORIENTACIÓN DE LAS PATAS } & $\mathrm{N}^{\circ}$ & $\%$ & $\mathrm{~N}^{\circ}$ & $\%$ & $\mathrm{~N}^{\circ}$ & $\%$ & $\mathrm{~N}^{\circ}$ & $\%$ & $\mathrm{~N}^{\circ}$ & $\%$ \\
\hline \multirow{4}{*}{ Flexionadas } & $\begin{array}{l}4 \text { patas flexionadas } \\
\text { hacia arriba }\end{array}$ & 0 & 0,00 & 0 & 0,00 & 14 & 29,79 & 6 & 100,00 & 20 & 16,81 \\
\hline & $\begin{array}{c}4 \text { patas flexionadas } \\
\text { hacia abajo }\end{array}$ & 0 & 0,00 & 3 & 5,77 & 2 & 4,26 & 0 & 0,00 & 5 & 4,20 \\
\hline & $\begin{array}{l}2 \text { patas flexionadas } \\
\text { hacia arriba y } 2 \text { patas } \\
\text { flexionadas hacia abajo }\end{array}$ & 5 & 35,71 & 38 & 73,08 & 23 & 48,94 & 0 & 0,00 & 66 & 55,46 \\
\hline & $\begin{array}{l}2 \text { patas flexionadas } \\
\text { hacia arriba }\end{array}$ & 0 & 0,00 & 0 & 0,00 & 1 & 2,13 & 0 & 0,00 & 1 & 0,84 \\
\hline \multirow[t]{2}{*}{ Extendidas } & $\begin{array}{l}2 \text { patas extendidas } \\
\text { hacia arriba y } 2 \text { patas } \\
\text { extendidas hacia abajo, } \\
\text { paralelas al cuerpo }\end{array}$ & 9 & 64,29 & 6 & 11,54 & 1 & 2,13 & 0 & 0,00 & 16 & 13,45 \\
\hline & $\begin{array}{l}4 \text { patas extendidas, } \\
\text { perpendiculares al cuerpo }\end{array}$ & 0 & 0,00 & 2 & 3,85 & 0 & 0,00 & 0 & 0,00 & 2 & 1,68 \\
\hline \multirow{3}{*}{ Combinadas } & $\begin{array}{c}2 \text { patas flexionadas hacia } \\
\text { arriba / abajo y } 2 \text { patas } \\
\text { extendidas, perpendiculares } \\
\text { al cuerpo }\end{array}$ & 0 & 0,00 & 2 & 3,85 & 0 & 0,00 & 0 & 0,00 & 2 & 1,68 \\
\hline & $\begin{array}{l}2 \text { patas flexionadas } \\
\text { hacia arriba y } 2 \text { patas } \\
\text { extendidas hacia arriba, } \\
\text { paralelas al cuerpo }\end{array}$ & 0 & 0,00 & 0 & 0,00 & 3 & 6,38 & 0 & 0,00 & 3 & 2,52 \\
\hline & $\begin{array}{l}2 \text { patas flexionadas } \\
\text { hacia arriba y } 2 \text { patas } \\
\text { indeterminadas }\end{array}$ & 0 & 0,00 & 1 & 1,92 & 0 & 0,00 & 0 & 0,00 & 1 & 0,84 \\
\hline Adosadas & 4 patas adosadas al cuerpo & 0 & 0,00 & 0 & 0,00 & 3 & 6,38 & 0 & 0,00 & 3 & 2,52 \\
\hline TOTAL & & 14 & 100 & 52 & 100 & 47 & 100 & 6 & 100 & 119 & 100 \\
\hline
\end{tabular}

En el PF sobresale la forma "Peiniforme sin base", seguida en menor cantidad por los dedos "Bifurcados" y los "Combinados". En el PIR casi la mitad de los ejemplos no tiene dedos representados. Entre las formas dominantes se encuentran los tipos "Peiniformes con base", seguidos de las opciones "Peiniformes sin base" y "Con cabezas de camélido".
Las representaciones de lagartijas correspondientes al PDR presentan en su mayoría dedos "Bifurcados", seguidos por los "Peiniforme con base" y los "Combinados". La opción "Con segmentos horizontales", aunque escasa, solo se reconoce en este período (fig. 2, B). Las figuras no asignadas carecen de dedos. 
Tabla 8. Forma de los dedos, discriminada por período. Table 8. Shape of fingers, per period.

\begin{tabular}{|c|c|c|c|c|c|c|c|c|c|c|}
\hline \multirow[b]{3}{*}{ FORMA DE LOS DEDOS } & \multicolumn{10}{|c|}{ PERÍODO } \\
\hline & \multicolumn{2}{|c|}{ FORMATIVO } & \multicolumn{2}{|c|}{$\begin{array}{l}\text { INTEGRACIÓN } \\
\text { REGIONAL }\end{array}$} & \multicolumn{2}{|c|}{$\begin{array}{l}\text { DESARROLLOS } \\
\text { REGIONALES }\end{array}$} & \multicolumn{2}{|c|}{ NO ASIGNADO } & \multicolumn{2}{|c|}{ TOTAL } \\
\hline & $\mathrm{N}^{\circ}$ & $\%$ & $\mathrm{~N}^{\circ}$ & $\%$ & $\mathrm{~N}^{\circ}$ & $\%$ & $\mathrm{~N}^{\circ}$ & $\%$ & $\mathrm{~N}^{\circ}$ & $\%$ \\
\hline Bifurcados & 2 & 14,29 & 4 & 7,69 & 31 & 65,96 & 0 & 0,00 & 37 & 31,09 \\
\hline Peiniformes sin base & 8 & 57,14 & 5 & 9,62 & 0 & 0,00 & 0 & 0,00 & 13 & 10,92 \\
\hline Peiniformes con base & 1 & 7,14 & 8 & 15,38 & 7 & 14,89 & 0 & 0,00 & 16 & 13,45 \\
\hline Con segmentos horizontales & 0 & 0,00 & 0 & 0,00 & 2 & 4,26 & 0 & 0,00 & 2 & 1,68 \\
\hline Con cabezas de felino & 0 & 0,00 & 1 & 1,92 & 0 & 0,00 & 6 & 100,00 & 1 & 0,84 \\
\hline Con cabezas de camélido & 0 & 0,00 & 5 & 9,62 & 0 & 0,00 & 0 & 0,00 & 5 & 4,20 \\
\hline Combinados & 2 & 14,29 & 4 & 7,69 & 5 & 10,64 & 0 & 0,00 & 11 & 9,24 \\
\hline No corresponde & 1 & 7,14 & 25 & 48,08 & 2 & 4,26 & 0 & 0,00 & 34 & 28,57 \\
\hline TOTAL & 14 & 100 & 52 & 100 & 47 & 100 & 6 & 100 & 119 & 100 \\
\hline
\end{tabular}

\section{Forma y terminación de las colas}

De la combinación de estas dos variables surgen 12 alternativas, siendo otro de los casos donde se puede apreciar la mezcla de atributos de diferentes grupos animales en una misma figura. Por ejemplo, se ha registrado un caso de cola con terminación en "Cabeza de felino" (tabla 9).

En la totalidad de casos estudiados predominan las colas "Rectas". Al interior de este grupo la terminación "En punta" es la más numerosa (fig. 1, B1), seguida en cantidad de ejemplos por la "Recta" (fig. 1, A3), la "Curva" (fig. 1, B2) y la "Abierta" (fig. 1, C1).

En el PF predominan las colas "Rectas" de terminación "En punta", con algunos casos de terminaciones "Rectas". Excepcionalmente se han encontrado ejemplos de colas "Sinuosas" con terminaciones "Curvas". Para este período no se han identificado colas "Curvas" ni "Dobles en zigzag". Entre las representaciones asignadas al PIR predominan las colas "Rectas" pero, en comparación con el período anterior, presentan más variabilidad en su terminación: "Recta", "Curva", "Abierta" y "En punta". En este período no se han registrado colas de forma "Sinuosa" ni "Doble en zigzag".
El PDR es el que presenta mayor variabilidad en cuanto a la forma de las colas y sus terminaciones. Predominan las colas con terminación "En punta", tanto de forma "Recta" como "Curva", seguidas por las colas "Doble en zigzag" con terminación "Abierta" (fig. 1, C1). En el conjunto analizado se encontraron cinco combinaciones exclusivas de este período: cola "Recta" con terminación "Tumiforme" (fig. 3, E), "Curva” con terminaciones "Recta" y "Abierta", "Sinuosa" con terminación "Recta" y "Doble en zigzag" con terminación "Abierta". Las representaciones no asignadas son en su totalidad de forma "Recta", con ejemplos de terminación "No determinada" y "Curva".

\section{Diseños internos}

Esta es una de las variables con mayores opciones, presentando un total de 12 alternativas (tabla 10). Al igual que el tipo de tratamiento, esta variable también se analizó para cada parte del cuerpo.

Cuando se observa la tabla 10 resulta evidente que no todas las partes del cuerpo presentan la misma cantidad de opciones para el diseño, algunas como las patas presentan pocas y otras como los cuerpos muchas 
Tabla 9. Forma y terminación de las colas, discriminadas por período. Table 9. Shape and ending of the tails, perperiod.

\begin{tabular}{|c|c|c|c|c|c|c|c|c|c|c|c|}
\hline & & \multicolumn{10}{|c|}{ PERÍODO } \\
\hline & & \multicolumn{2}{|c|}{ FORMATIVO } & \multicolumn{2}{|c|}{$\begin{array}{l}\text { INTEGRACIÓN } \\
\text { REGIONAL }\end{array}$} & \multicolumn{2}{|c|}{$\begin{array}{c}\text { DESARROLLOS } \\
\text { REGIONALES }\end{array}$} & \multicolumn{2}{|c|}{ NO ASIGNADO } & \multicolumn{2}{|c|}{ TOTAL } \\
\hline \multicolumn{2}{|c|}{ FORMA Y TERMINACIÓN DE LAS COLAS } & $\mathrm{N}^{\circ}$ & $\%$ & $\mathrm{~N}^{\circ}$ & $\%$ & $\mathrm{~N}^{\circ}$ & $\%$ & $\mathrm{~N}^{\circ}$ & $\%$ & $\mathrm{~N}^{\circ}$ & $\%$ \\
\hline \multirow{6}{*}{ Recta } & Recta & 4 & 28,57 & 20 & 38,46 & 1 & 2,13 & 0 & 0,00 & 25 & 21,01 \\
\hline & Curva & 0 & 0,00 & 11 & 21,15 & 3 & 6,38 & 2 & 33,33 & 16 & 13,45 \\
\hline & En punta & 8 & 57,14 & 4 & 7,69 & 20 & 42,55 & 0 & 0,00 & 32 & 26,89 \\
\hline & Abierta & 0 & 0,00 & 10 & 19,23 & 0 & 0,00 & 0 & 0,00 & 10 & 8,40 \\
\hline & Tumiforme & 0 & 0,00 & 0 & 0,00 & 1 & 2,13 & 0 & 0,00 & 1 & 0,84 \\
\hline & No determinada & 0 & 0,00 & 0 & 0,00 & 0 & 0,00 & 4 & 66,67 & 4 & 3,36 \\
\hline \multirow{4}{*}{ Curva } & Recta & 0 & 0,00 & 0 & 0,00 & 2 & 4,26 & 0 & 0,00 & 2 & 1,68 \\
\hline & En punta & 0 & 0,00 & 0 & 0,00 & 7 & 14,89 & 0 & 0,00 & 7 & 5,88 \\
\hline & Abierta & 0 & 0,00 & 0 & 0,00 & 3 & 6,38 & 0 & 0,00 & 3 & 2,52 \\
\hline & Con cabeza de felino & 0 & 0,00 & 1 & 1,92 & 0 & 0,00 & 0 & 0,00 & 1 & 0,84 \\
\hline \multirow{2}{*}{ Sinuosa } & Recta & 0 & 0,00 & 0 & 0,00 & 2 & 4,26 & 0 & 0,00 & 2 & 1,68 \\
\hline & Curva & 2 & 14,29 & 0 & 0,00 & 0 & 0,00 & 0 & 0,00 & 2 & 1,68 \\
\hline Doble en zigzag & Abierta & 0 & 0,00 & 0 & 0,00 & 4 & 8,51 & 0 & 0,00 & 4 & 3,36 \\
\hline No corresponde & No corresponde & 0 & 0,00 & 4 & 7,69 & 4 & 8,51 & 0 & 0,00 & 8 & 6,72 \\
\hline No determinada & No determinada & 0 & 0,00 & 2 & 3,85 & 0 & 0,00 & 0 & 0,00 & 2 & 1,68 \\
\hline TOTAL & & 14 & 100 & 52 & 100 & 47 & 100 & 6 & 100 & 119 & 100 \\
\hline
\end{tabular}

opciones. Asimismo, no todas las partes del cuerpo se decoran con los mismos diseños. Por otra parte, en todos los períodos se encuentran opciones combinadas, que son mucho más frecuentes en cuerpos que en cabezas, patas o colas. Algunos de los motivos que componen las alternativas combinadas no se registran como categoría de manera individual (por ejemplo, cuadrados, óvalos y escaleriformes) sino que siempre están acompañados por otros diseños.

La gran mayoría de las cabezas no presenta diseños internos. Cuando hay diseños, dominan las "Líneas horizontales paralelas", seguidas de "Puntos / Trazos".
Resulta llamativo que varios de los diseños disponibles para las lagartijas en general, no se utilizan para las cabezas en particular (por ejemplo "Círculos", "Líneas verticales paralelas", "Líneas sinuosas" y "Damero"). Si consideramos esta información discriminada por período, en las cabezas decoradas del PF, PIR y PDR se destacan las "Líneas horizontales paralelas" (fig. 1, A1) mientras que aquellas no asignadas carecen de decoración.

En el caso de los cuerpos, también dominan aquellos sin diseños internos (fig. 1, B4 y C3). Entre los diseños presentes se destacan en este caso las "Líneas horizontales paralelas" seguidos por las combinacio- 
Tabla 10. Diseños internos, por partes del cuerpo. Table 10. Inner designs, per body part.

\begin{tabular}{|c|c|c|c|c|c|c|c|c|}
\hline \multirow[b]{3}{*}{ DISEÑOS INTERNOS } & \multicolumn{8}{|c|}{ PARTES DEL CUERPO } \\
\hline & \multicolumn{2}{|c|}{ CABEZA } & \multicolumn{2}{|c|}{ CUERPO } & \multicolumn{2}{|c|}{ PATAS } & \multicolumn{2}{|c|}{ COLA } \\
\hline & $\mathrm{N}^{\circ}$ & $\%$ & $\mathrm{~N}^{\circ}$ & $\%$ & $\mathrm{~N}^{\circ}$ & $\%$ & $\mathrm{~N}^{\circ}$ & $\%$ \\
\hline Puntos / Trazos & 6 & 4,88 & 1 & 0,84 & 6 & 5,04 & 10 & 8,40 \\
\hline Círculos & 0 & 0,00 & 2 & 1,68 & 2 & 1,68 & 2 & 1,68 \\
\hline Círculos con punto & 1 & 0,81 & 1 & 0,84 & 1 & 0,84 & 1 & 0,84 \\
\hline Líneas horizontales paralelas & 17 & 13,82 & 25 & 21,01 & 7 & 5,88 & 14 & 11,76 \\
\hline Líneas verticales paralelas & 0 & 0,00 & 1 & 0,84 & 2 & 1,68 & 3 & 2,52 \\
\hline Líneas diagonales paralelas & 1 & 0,81 & 1 & 0,84 & 0 & 0,00 & 0 & 0,00 \\
\hline Líneas sinuosas & 0 & 0,00 & 1 & 0,84 & 0 & 0,00 & 1 & 0,84 \\
\hline Rombo/s & 3 & 2,44 & 8 & 6,72 & 0 & 0,00 & 0 & 0,00 \\
\hline Reticulado & 1 & 0,81 & 3 & 2,52 & 1 & 0,84 & 1 & 0,84 \\
\hline Damero & 0 & 0,00 & 7 & 5,88 & 0 & 0,00 & 3 & 2,52 \\
\hline Triángulos espiralados con o sin apéndice & 1 & 0,81 & 3 & 2,52 & 0 & 0,00 & 0 & 0,00 \\
\hline Combinado & 2 & 1,63 & 20 & 16,81 & 2 & 1,68 & 4 & 3,36 \\
\hline No corresponde & 87 & 70,73 & 45 & 37,82 & 98 & 82,35 & 78 & 65,55 \\
\hline No determinado & 4 & 3,25 & 1 & 0,84 & 0 & 0,00 & 2 & 1,68 \\
\hline TOTAL & 123 & 100 & 119 & 100 & 119 & 100 & 119 & 100 \\
\hline
\end{tabular}

nes de diseños individuales en una misma figura. Se trata de la única parte del cuerpo que presenta todas las alternativas de la variable diseños internos. Los cuerpos decorados en el PF presentan mayormente "Líneas horizontales paralelas". Para el PIR y el PDR la opción más utilizada es la combinación de diseños, estando también presentes las "Líneas horizontales paralelas", los "Rombos" y el "Damero". Las lagartijas cuya asignación cronológica no ha podido ser determinada carecen de decoración.

En las patas nuevamente dominan los casos sin diseños internos y, cuando hay algún diseño, solo están representadas alrededor de la mitad de las opciones disponibles. $\mathrm{Al}$ igual que en las cabezas abundan las "Líneas horizontales paralelas" y los "Puntos/Trazos" (fig. 1, B1).El PF muestra muy escasos ejemplos de patas decoradas. El PIR es el que presenta mayor cantidad de casos de patas decoradas y, entre los diseños más utilizados, se pueden mencionar los "Puntos/Trazos" y las "Líneas horizontales paralelas". En el PDR y en los casos no asignados no se hallaron patas decoradas.

Tal como sucede con las otras partes del cuerpo, las colas suelen representarse sin diseños internos y, cuando estos aparecen, nuevamente predominan las "Líneas horizontales paralelas" y los "Puntos / Trazos". $\mathrm{Al}$ igual que en el caso de las patas, en el PF las colas decoradas son excepcionales. En el PIR y el PDR, si bien predominan las "Líneas horizontales paralelas", también se registran los "Puntos/Trazos". En las representaciones cuya asignación cronológica se desconoce no se identificaron colas decoradas. 
Tabla 11. Tipo de unión entre las diferentes partes del cuerpo. Table 11. Connection type between the different parts of the body.

\begin{tabular}{|c|c|c|c|c|c|c|}
\hline \multirow[b]{2}{*}{ TIPO DE UNIÓN } & \multicolumn{2}{|c|}{ CABEZA Y CUERPO } & \multicolumn{2}{|c|}{ CUERPO Y PATAS } & \multicolumn{2}{|c|}{ CUERPO Y COLA } \\
\hline & $\mathrm{N}^{\circ}$ & $\%$ & $\mathrm{~N}^{\circ}$ & $\%$ & $\mathrm{~N}^{\circ}$ & $\%$ \\
\hline Continua & 91 & 76,47 & 68 & 57,14 & 94 & 78,99 \\
\hline Discontinua & 28 & 23,53 & 51 & 42,86 & 18 & 15,13 \\
\hline No corresponde & 0 & 0,00 & 0 & 0,00 & 6 & 5,04 \\
\hline No determinada & 0 & 0,00 & 0 & 0,00 & 1 & 0,84 \\
\hline TOTAL & 119 & 100 & 119 & 100 & 119 & 100 \\
\hline
\end{tabular}

\section{Tipo de unión}

Se analizaron tres tipos de uniones entre las diferentes partes del cuerpo: a) entre cabeza y cuerpo, b) entre cuerpo y patas y c) entre cuerpo y cola con dos alternativas cada una (tabla 11). En todos los casos domina la opción "Continua" en detrimento de la "Discontinua", aunque no siempre domina con los mismos porcentajes.

Considerando solo la unión de cabeza y cuerpo, en todos los períodos predomina la unión "Continua". Para la unión entre cuerpo y patas, en el PF se registran más casos de uniones "Discontinuas" (fig. 1, A1) que "Continuas" (fig. 1, A3). Tanto en el PIR como en el PDR se invierte esta tendencia. En la totalidad de los casos no asignados se observan uniones "Continuas". En cuanto a la unión de cuerpo y cola en el PF predomina el tipo "Discontinuo". Tanto en el PIR como en el PDR y en los ejemplos cuya cronología no ha podido establecerse se registra una mayor cantidad de casos de unión "Continua”.

\section{DISCUSIÓN Y CONSIDERACIONES FINALES}

A través de la cuantificación de los datos surgieron tendencias que no se habían percibido solo con la observación, a la vez que se corroboraron otras cuestiones notadas durante la descripción y análisis de las imágenes. Asimismo, se identificaron tendencias por parte del cuerpo, así como también por período.

Somos conscientes que el número de representaciones de nuestra muestra por período es desigual. Sin embargo, creemos que este dato también es informativo ya que podría estar indicando una importancia relativa diferencial de la lagartija a lo largo del tiempo.

El número de ejemplos analizados no solo es desigual a nivel temporal sino también espacial. Aun cuando se buscaron representaciones de todo el NOA, hay regiones como la Puna para las cuales no se encontraron casos.

Finalmente, la muestra relevada también es desigual en cuanto a los soportes utilizados. Las 119 representaciones analizadas incluyen: 79 piezas cerámicas (de todos los períodos), 22 motivos de arte rupestre (de todos los períodos), 16 piezas de metalurgia (adscriptas solamente al PDR), un vaso de piedra (del PF) y una espátula de hueso (del PIR).

\section{Acerca de la complejidad en el modo de representación de las lagartijas}

La complejidad de las representaciones de la muestra analizada se observó en dos niveles o aspectos: 1) en la cantidad de atributos presentes de varios grupos animales y 2) en la cantidad de combinaciones de tipos incluidos, ambos casos en una misma figura.

En lo que respecta al primer nivel, Gordillo (1998), en un trabajo sobre una muestra de alfarería de Ambato (atribuida al PIR), clasifica a los motivos zoomorfos como simples (representan una sola especie) o compuestos (combinan en una misma imagen atributos de más de una especie y pueden aludir a imágenes reales o fantásticas).

Cabe mencionar que en el conjunto analizado en este trabajo la combinación con otras especies se aprecia en cabezas, patas y colas, no así en cuerpos. La articulación 
con partes del cuerpo de otros grupos animales en una misma figura solo se ha registrado en el PIR y en el PDR, aunque con mayor variabilidad en el primero. Así, en este período se reconocen lagartijas con dedos felinizados o con dedos con forma de cabezas de felinos o camélidos o con colas terminadas en cabezas de felino (fig. 3). Algunas de las representaciones que para este análisis fueron incluidas como lagartijas, fueron consideradas por otros autores como felinos por la presencia de fauces. Por otro lado, en el PDR se registró en más de un caso la combinación de lagartijas con antropomorfos, dando como resultado figuras extremadamente ambiguas en las cuales se puede discutir si se trata de antropomorfos con la manera típica de representar las extremidades de las lagartijas o bien de lagartijas con cabeza humana (fig. 3, E). En este caso, la presencia de ojos y bocas en las cabezas sugieren una representación de frente, como en la mayoría de los antropomorfos.

La manera de representar las lagartijas es menos compleja que la de los serpentiformes, particularmente los del PIR. En este período se observan casos con más de dos cabezas (fig. 4, A1 y A2), combinación de dos (ofidio-felino) (fig. 4, B1 y B2) y hasta tres grupos animales (ofidio-felino-antropomorfo) en una misma figura (fig. 4, C1 y C2). En las lagartijas existe la combinación con atributos de varios grupos animales, pero no con todos a la vez. Como máximo se observan dos grupos en una misma figura (lagartija-felino, lagartija-camélido o lagartija-antropomorfo) (fig. 3). Asimismo, en el caso de las lagartijas se registran ejemplos de un cuerpo con dos cabezas, pero nunca dos individuos completos articulados en la misma figura, como sí sucede con los serpentiformes (fig. 4, A1).

Respecto del segundo nivel de complejidad, cabe mencionar que a lo largo del tiempo los motivos de lagartijas combinan cada vez más tipos en una misma representación. Si bien hay diseños simples en todos los períodos (por ejemplo, sin ningún atributo de la cabeza ni decoración), es más probable encontrar casos que combinen muchos tipos en el PDR que en los períodos anteriores (fig. 1, C1 y C2). Por ejemplo, una forma de cabeza se puede combinar con distintas formas de cuerpos, patas y colas o una misma posición y orientación de las patas se puede combinar con distintos diseños internos de los cuerpos.

Asimismo, a través de los sucesivos períodos se combinan cada vez más variantes de diseños internos en un mismo motivo (fig. 2, B y C). Por esta razón las representaciones asignadas al PDR presentan una variabilidad morfológica que será necesario rastrear en los diferentes estilos del NOA (por ejemplo, Belén o Santa María) para identificar potenciales variaciones regionales dentro del mencionado período.

\section{Acerca de la bicefalia en las lagartijas}

Con respecto a la bicefalia, si bien en la naturaleza hay casos de dos cabezas - una al lado de la otra, así como de una cabeza en cada extremo del cuerpo-, en las ilustraciones siempre se muestra una en cada extremo del cuerpo. Esto sucede tanto en lagartijas como en serpentiformes (fig. 5). La bicefalia en las lagartijas, registrada en la iconografía de la muestra aquí analizada correspondiente al PIR y al PDR, no es tan conspicua como en los serpentiformes estudiados previamente (Kligmann \& Díaz País 2007, Kligmann et al. 2013).

Asimismo, se puede apreciar que, en el caso de las lagartijas, cuando son bicéfalas, parte de sus cuerpos desaparecen para permitir la creación del segundo individuo. Cada animal presenta solo las patas delanteras mientras las traseras pasan a constituir las patas delanteras del animal opuesto, sin representarse ninguna de las dos colas. En el caso de los serpentiformes, el único indicador de bicefalia es la segunda cabeza, que se agrega en lugar de la cola. Así, el individuo no pierde ninguna parte del cuerpo (fig. 5). Incluso se han observado casos de serpentiformes bicéfalos articulados, dando lugar a ejemplos de dos cuerpos con tres cabezas (fig. 5, D2).

Si bien ambos animales, cuando son bicéfalos, suelen estar representados de manera espejada y/o simétrica, si el serpentiforme bicéfalo pierde una de sus cabezas sigue siendo un serpentiforme. La lagartija bicéfala sin una de sus cabezas queda incompleta y no necesariamente se entiende como un animal individual (fig. 5).

Si se descomponen las imágenes tomando en cuenta las partes del cuerpo, se puede apreciar que mientras que en los serpentiformes se trata claramente de un cuerpo con dos cabezas, el caso de las lagartijas da lugar a una duda sobre si se trata de un cuerpo con dos cabezas o de dos cuerpos incompletos ensamblados, con una cabeza cada uno (fig. 5).

Luego de haber elaborado una tipología específica para lagartijas y contando con nuevos ejemplos, una figura que en un trabajo previo (Kligmann \& Díaz País 2007, fig. 8.94, pp. 85) había sido considerada como serpentiforme, en esta ocasión fue reinterpretada como lagartija 


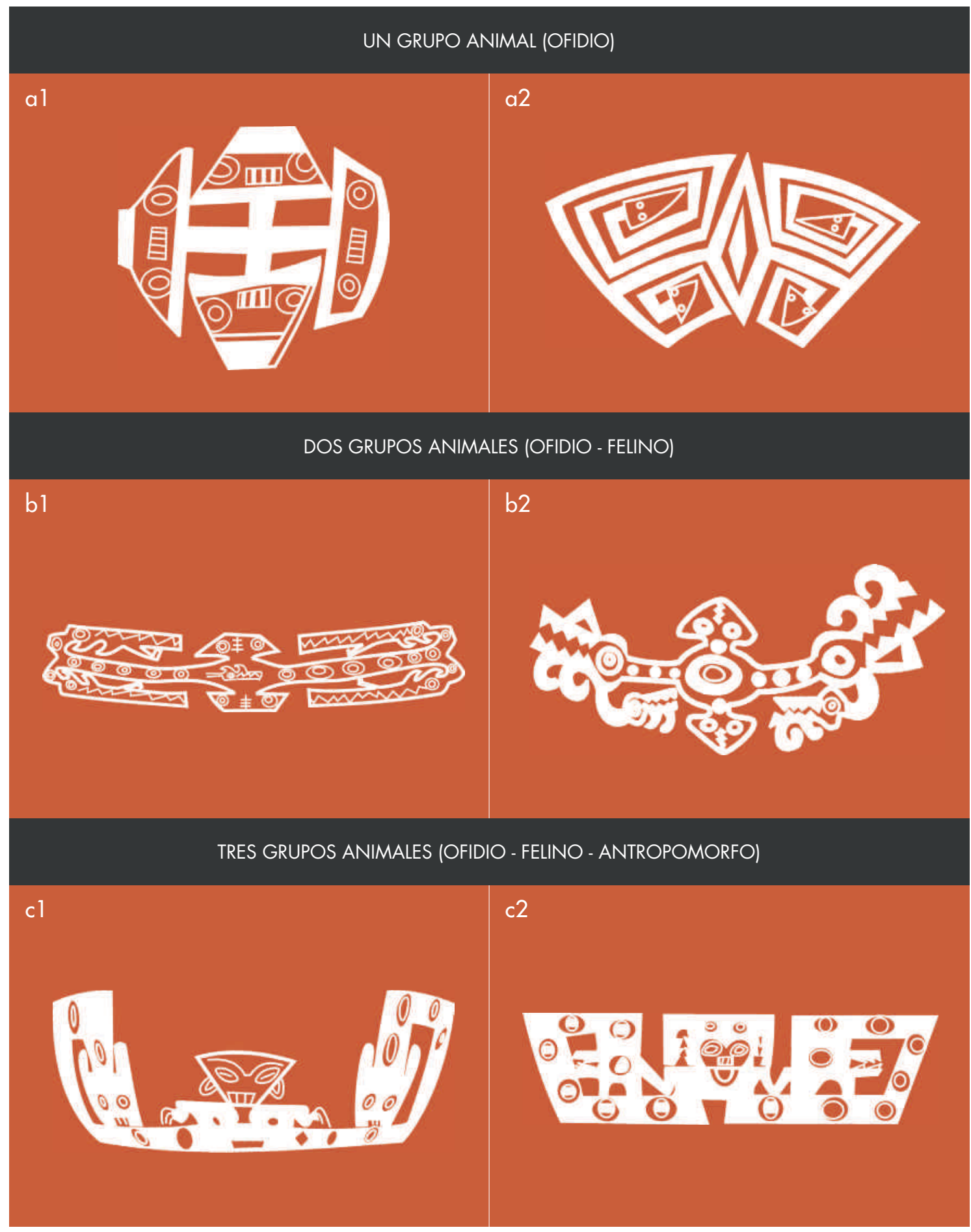

Figura 4. Ejemplos de serpentiformes con más de dos cabezas del PIR (las imágenes utilizadas fueron adaptadas de los siguientes textos: A1: González 1998: xviII; A2: González 1998: xvi; B1: Bedano et al. 1993: 111; B2: Bedano et al. 1993: 115; C1: González 1998: 171; C2: Sempé \& Baldini 2004: 280). Figure 4. Examples of serpent-shaped images with more than two heads from the RIP (the images were adapted from the following texts: A1: González 1998: XVIII; A2: González 1998: XVI; B1: Bedano et al. 1993: 111; B2: Bedano et al. 1993 : 115; C1: González 1998: 171; C2: Sempé \& Baldini 2004: 280). 


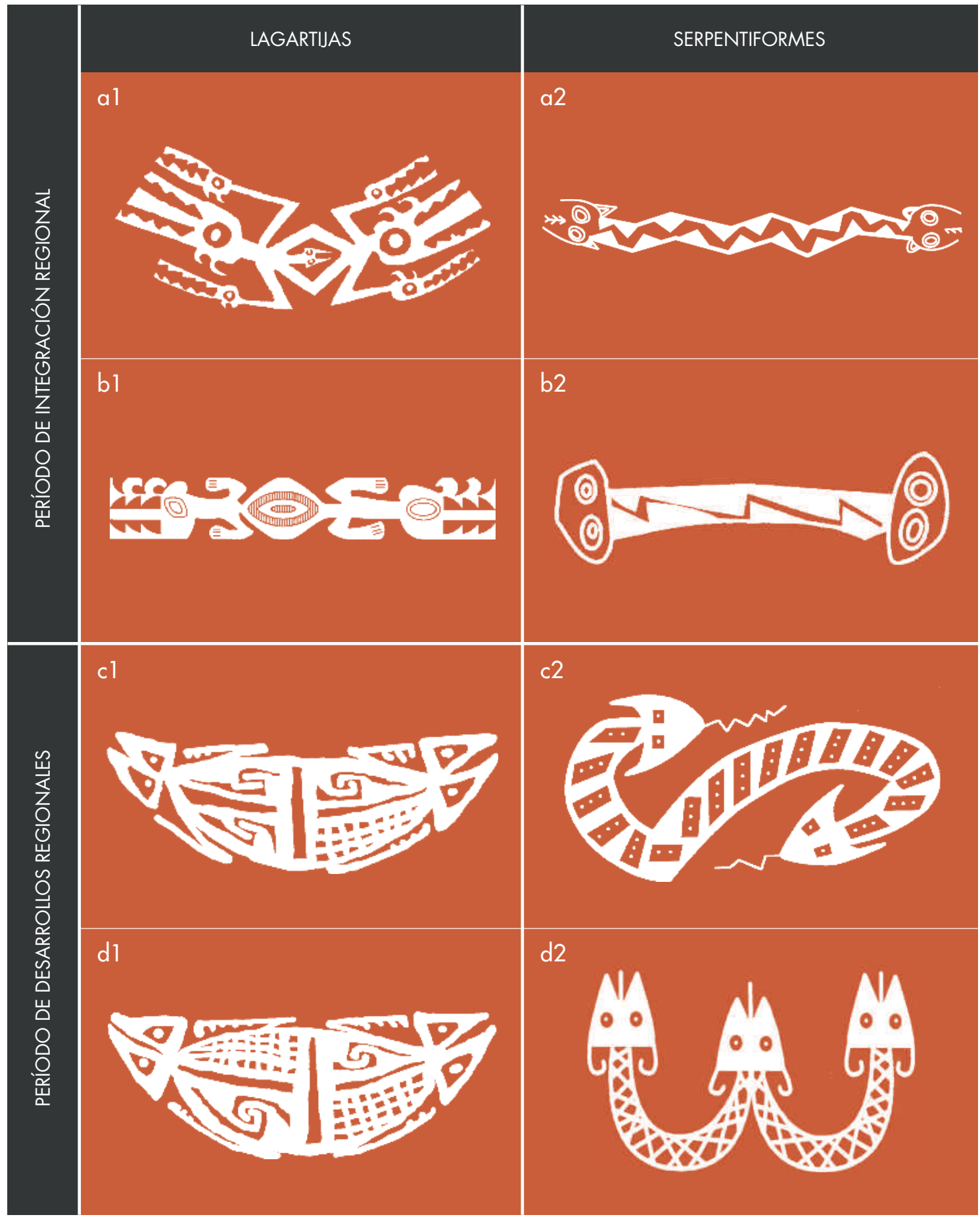

Figura 5. Ejemplos de lagartijas y serpentiformes bicéfalos del PIR y del PDR (las imágenes utilizadas fueron adaptadas de los siguientes textos y piezas: A1: Lafone Quevedo 1908: 373; A2: González 1998: 265; B1: Fiadone 2001: 108; B2: González 1998: 153; C1 y D1: Pieza 586, Museo Nacional del Hombre (INAPL); C2 y D2: Albuerne, Díaz \& Zárate 1999: 83). Figure 5. Examples of lizards and two-headed serpent-shaped images from the RIP and the RDP (the images were adapted from the following texts and pieces: A1: Lafone Quevedo 1908: 373; A2: González 1998: 265; B1: Fiadone 2001: 108; B2: González 1998: 153; C1 and D1: Piece 586, National Museum of man (INAPL); C2 and D2: Albuerne, Díaz \& Zárate 1999: 83). 
(fig. 5, A1). En un primer momento se la describió como tres serpientes bicéfalas combinadas y posteriormente como una lagartija bicéfala con 2 patas flexionadas hacia arriba y 2 patas flexionadas hacia abajo. Lejos de suponer un conflicto se considera que la ambigüedad es una característica sobresaliente del arte prehispánico que está siempre latente en los análisis iconográficos.

Desde el punto de vista del diseño se podría plantear que los serpentiformes combinan menos elementos que las lagartijas. Por ejemplo, en estas últimas se observa una reflexión tanto longitudinal como transversal en ambos períodos (PIR y PDR), articulando los diferentes campos con diseños internos (Hernández Llosas \& Podestá 1985), característica que no se registra en el PF.

Como ya ha sido señalado para las urnas santamarianas (Nastri 2005), muchos de los motivos bicéfalos presentan una simetría imperfecta o diferencia sutil. Teniendo en cuenta el grado de detalle y elaboración de las decoraciones del PIR y del PDR, cuesta creer que estas diferencias sutiles no hayan sido intencionales con la finalidad de transmitir un mensaje. No se trataría entonces de "errores" de diseño, sino de una imperfección deliberada de los artesanos.

Esta simetría alterada por algún pequeño detalle, resulta en individuos similares o parecidos pero diferentes. Por ejemplo, en la figura 5 D1, se observa un caso de simetría rotacional, donde los mismos diseños internos se disponen de modo invertido en torno a un punto. Si bien la figura 5 C1 parecería presentar un caso similar a la D1, el diseño interno de uno de los campos no cumple con los principios de simetría, conformando un ejemplo de diferencia sutil respecto de la figura 5 D1. Ambos individuos bicéfalos forman parte de la decoración interna de un puco, con lo cual la diferencia sutil se observa a nivel del diseño de la pieza. En la figura $5 \mathrm{~B} 1$, en cambio, se representa un caso de simetría bilateral o reflexión de espejo, que se da cuando se genera una relación de carácter especular entre dos motivos (Nastri 2005).

\section{Acerca del modo de representación de las lagartijas y de los tipos exclusivos de cada período}

Una de las consecuencias más relevantes de este análisis ha sido la identificación del modo de representación de las lagartijas en los distintos períodos considerados, así como de los tipos exclusivos de cada uno de ellos. Así, uno de los aportes de este trabajo consiste en contribuir a la asignación cronológica de representaciones de contextos desconocidos. Sin embargo, no se desconoce que existen otras vías para explorar en relación a las formas de representación y sus variantes cronológicas relativas, las cuales exceden los fines de este trabajo.

\section{Período Formativo}

Las lagartijas del PF solo se representan en "Planta". Domina el tratamiento "Lineal" sobre el "Plano" en todas las partes del cuerpo y el tipo de tratamiento no se combina en las diferentes partes, sino que se utiliza siempre el mismo tipo para toda la figura.

Tanto para las cabezas como para los cuerpos dominan las formas "Romboidales" de contorno "Recto". Los atributos de la cabeza están prácticamente ausentes, habiéndose hallado solo un caso con ojos y otro con cuello.

Siempre presentan " 2 patas hacia arriba y 2 hacia abajo", en sus variantes extendidas o flexionadas. Para los dedos de las patas, la forma dominante es la "Peinforme sin base". En las colas dominan las formas "Rectas", con terminación "En punta" o "Recta".

Para el diseño interno se observa que abunda la falta de decoración; en aquellos casos en los que esta está presente dominan las "Líneas horizontales paralelas".

En el conjunto analizado se destaca la unión de tipo "Continua" para cabeza y cuerpo y la "Discontinua" para cuerpo y patas y para cuerpo y cola. Así, no siempre se utiliza el mismo tipo de unión para todas las partes del cuerpo, sino que las diferentes opciones aparecen combinadas en una misma figura.

Las únicas variables de este período que presentan características exclusivas son: 1) la forma y terminación de las colas, con la forma "Sinuosa" de terminación "Curva" y 2) los diseños internos, con los tipos "Círculo con punto" y "Líneas diagonales paralelas".

\section{Período de Integración Regional}

Si bien la vista de las figuras de este período es variable, domina ampliamente la opción en "Planta" así como el tratamiento "Lineal" en todas las partes del cuerpo. Las lagartijas del PIR son las que combinan más elementos o atributos de diferentes grupos animales en una misma figura.

Tanto para las cabezas como para los cuerpos se observa un predominio de formas "Romboidales" de 
contorno "Recto". Como ya se mencionó en los resultados, este es el único período en el cual se registran todos los atributos de las cabezas.

Abundan las patas flexionadas, en su combinación "2 hacia arriba y 2 hacia abajo". La mayoría de las figuras no presentan dedos ni decoración interna. Dominan las colas "Rectas" de terminación "Recta" y el tipo de unión "Continua" para todas las partes del cuerpo.

Entre los atributos exclusivos para este período se pueden mencionar: 1) la vista, con sus tipos "Planta/ Perfil A" y "Planta/Perfil B1", 2) la forma de la cabeza ("Circular con apéndices"), 3) la forma de los cuerpos ("Circular" de contorno "Curvo" e "Irregular" de contorno "Recto"), 4) la forma de las patas ("4 patas extendidas" y "2 patas flexionadas hacia arriba / abajo y 2 patas extendidas", ambas perpendiculares al cuerpo), 5) la forma de los dedos ("Con cabezas de felino" y "Con cabezas de camélido"), 6) la forma de las colas ("Recta" de terminación "Abierta" y "Curva" terminada con "Cabeza de felino") y 7) los diseños internos ("Círculos" y "Líneas verticales paralelas").

\section{Período de Desarrollos Regionales}

La vista de las figuras de este período se distribuye en partes casi iguales entre "Planta" y "Planta/Perfil B2". No existe una opción predominante en cuanto al tipo de tratamiento de las figuras.

Entre las formas de las cabezas y de los cuerpos predominan las "Ovaladas" de contorno "Curvo". Se presentan casi todos los atributos de las cabezas, excepto los dientes.

En lo que respecta a las formas de las patas, la dominante es la de "2 patas flexionadas hacia arriba y 2 patas flexionadas hacia abajo". Entre los dedos predominan los "Bifurcados". En lo que respecta a las colas, abundan aquéllas "Rectas" con terminación "En punta".

Sobresalen las figuras sin diseños internos. En cuanto al tipo de unión, para la unión cabeza y cuerpo y para la unión cuerpo y cola se destaca la "Continua" mientras que para la unión cuerpo y patas los casos se distribuyen en partes casi iguales entre las opciones "Continua" y "Discontinua".

Respecto de los tipos exclusivos se pueden mencionar las siguientes variables: 1) forma de las cabezas ("Triangular simple invertida", "Triangular doble, con base doble", "Rectangular" y "Romboidal doble"), 2) forma de los cuerpos ("Almendrada"), 3) forma de las patas ("4 patas flexionadas hacia arriba", "2 patas flexionadas hacia arriba y 2 patas extendidas hacia arriba, paralelas al cuerpo" y "4 patas adosadas al cuerpo"), 4) forma de los dedos ("Con segmentos horizontales"), 5) forma y terminación de la cola ("Recta" de terminación "Tumiforme", "Curva" de terminación "Recta", "Curva" de terminación "Abierta", "Sinuosa" de terminación "Recta" y "Doble en zigzag" de terminación "Abierta") y 6) diseños internos ("Líneas sinuosas", "Damero" y "Triángulos espiralados").

\section{Consideraciones finales}

Consideramos importante destacar la utilidad de las tipologías como herramientas analíticas que permiten analizar un gran volumen de datos, encontrar patrones comunes a varios motivos, así como características exclusivas de diferentes períodos.

El análisis detallado de las lagartijas nos permitió refinar los criterios para la asignación de los motivos a grupos animales específicos, reevaluando algunos casos que en el pasado se habían adscripto a otros grupos.

De las 11 variables analizadas, por el momento dos de ellas no arrojaron tendencias claras: 1) Tipo de tratamiento y 2) Tipo de unión. Posiblemente brinden información complementaria cuando se analicen las representaciones teniendo en cuenta otras variables tales como el soporte y las técnicas de ejecución. De todos modos, cabe aclarar que ambas variables están íntimamente relacionadas con decisiones estilísticas que podrían ser independientes de los materiales empleados.

Por otra parte, cinco de las variables consideradas no resultaron determinantes a la hora de definir una lagartija: 1) contorno y forma de la cabeza, 2) atributos de la cabeza, 3) contorno y forma del cuerpo, 4) dedos y 5) diseños internos. Por ejemplo, no se esperaría encontrar representaciones de lagartijas con cabezas semicirculares y sin embargo las hay. En las formas de los cuerpos también se identificaron ejemplos que no existen en la naturaleza, como ser lineales o rectangulares. A su vez, la mayoría de los casos analizados no presenta atributos en las cabezas, que sí existen en las lagartijas reales. Lo mismo sucede con las patas, ya que muchas de las figuras analizadas no tienen dedos. Cuando se ilustran, el número es variable mientras que las lagartijas vivas tienen cinco dedos en cada extremidad. Finalmente, hay una gran diversidad de diseños internos, pero ninguno de ellos remite a la piel de los 
animales, como sí sucede en el caso de las anfisbenas y los serpentiformes analizados previamente (Kligmann et al. 2013, Kligmann \& Díaz País 2007).

Así, se puede apreciar que ninguna variable por sí sola aporta datos concluyentes para la asignación animal, siendo la combinación de varios atributos la que permite afirmar si se trata o no de lagartijas.

Esperamos que esta propuesta resulte de utilidad no solo para el análisis de las lagartijas sino también para otros animales poco representados en la iconografía prehispánica del NOA, como pueden ser batracios y aves.

La metodología elaborada, así como los resultados alcanzados, pueden ser utilizados por investigaciones en el campo de la iconografía del NOA así como de otras regiones del país y de países vecinos. No se descarta que en el futuro se amplíe la base de datos y la cantidad de tipos de cada variable, a través del aporte de nuevos hallazgos.

Agradecimientos A Mara Basile e Inés Gordillo por la invitación para publicar en este volumen. A Kevin Lane por revisar el abstract. A Mara Basile por haber compartido gentilmente dos figuras de su tesis de licenciatura para este trabajo. A Gisela Spengler por su invalorable aporte en la edición final de las figuras. A los evaluadores anónimos por sus valiosos comentarios que nos ayudaron a mejorar el manuscrito original.

\section{REFERENCIAS}

Albino, A. M. \& Kligmann, D. M. 2007. An accumulation of bone remains of two Liolaemus species (Iguanidae) in an Holocene archaeological site of the Argentine puna. Amphibia-Reptilia 28 (1): 154-158.

Albino, A. M. \& Kligmann, D. M. 2009. Inusual hallazgo de anfisbénidos (Squamata, Amphisbaenidae) en un yacimiento arqueológico de Argentina. Revista Española de Herpetología 23: 99-106.

Albuerne, I., Díaz, Y. \& ZÁrate, V. 1999. Diseños indígenas argentinos. Buenos Aires: Emecé.

Ambrosetti, J. B. 1899. Notas de arqueología calchaquí. Buenos Aires: "La Buenos Aires".

Arnheim, R. 1985. Arte y percepción visual. Madrid: Alianza.

Aschero, C. 2000. Figuras humanas, camélidos y espacios en la interacción circumpuneña. En Arte en las rocas. Arte rupestre, menhires y piedras de colores en Argentina, M. M. Podestá \& M. de Hoyos, Eds., pp. 15-44. Buenos Aires: Sociedad Argentina de Antropología.

BALESTA, B. 2015. Interpretaciones semióticas sobre imágenes de camélidos en el Noroeste Argentino. Boletín del Museo Chileno de Arte Precolombino 20 (1): 9-28.
BAsile, M. 2005. Iconografía funeraria Belén: aportes para la definición de un estilo decorativo. Tesis de Licenciatura en Ciencias Antropológicas, Facultad de Filosofía y Letras, Universidad de Buenos Aires.

Bedano, M. C., Juez, M. S. \& RocA, M. D. 1993 Ms. Análisis del material arqueológico de la Colección Rosso procedente del Departamento de Ambato, Provincia de Catamarca. Serie tesis y monografías $n^{\circ} 1$, publicaciones del Instituto de Arqueología 7, Universidad Nacional de Tucumán, San Miguel de Tucumán.

Callegari, A. 2004. Las poblaciones precolombinas que habitaron el sector central del Valle de Vinchina entre el 900/950 y 1600/1650 DC (Dto. General Lamadrid, La Rioja, Argentina). Relaciones de la Sociedad Argentina de Antropología xxix: 81-110.

De hoyos, M. C. 2013. Cuerpos imaginados. Variaciones en la representación de la figura humana en el arte rupestre de la zona valliserrana del Noroeste Argentino. Tesis para optar al grado de Doctor en Arqueología, Facultad de Filosofía y Letras, Universidad de Buenos Aires.

Falchi, M. P. \& Podestá, M. M. 2015. "Aquí estuvimos, por acá pasamos". Grabados de pisadas y huellas humanas en los desiertos sur andinos. Arkeos 37: 289-312.

Falchi, M. P., Podestá, M. M., Rolandi, D., Re, A. \& Torres, M. A. 2011. Arte rupestre entre las sierras y los llanos riojanos: localidad arqueológica Palancho. Comechingonia 15: 39-63.

Falchi, M. P., Podestá, M. M., Rolandi, D. \& Torres, M. A. 2013. Grabados rupestres en el desierto rojo, Los Colorados (La Rioja, Argentina). Mundo de Antes 8: 105-130.

Ferraro, L. 2005. Los Pizarrones: investigación, conservación y difusión de arte rupestre en el Parque Nacional Talampaya. Tesis de Licenciatura en Ciencias Antropológicas, Facultad de Filosofía y Letras, Universidad de Buenos Aires.

FiAdone, A. 2001. El diseño indígena argentino. Una aproximación a la iconografía precolombina. Buenos Aires: La Marca.

Garin, C. \& Hussein, Y. 2013. Guía de reconocimiento de anfibios y reptiles de la Región de Valparaíso. Valparaíso: Servicio Agrícola y Ganadero, Ministerio de Agricultura.

González, A. R. 1977. Arte precolombino de la Argentina. Buenos Aires: Filmediciones Valero.

González, A. R. 1992. Las placas metálicas de los Andes del sur. Contribución al estudio de las religiones precolombinas. Mainz am Rhein: Kava Band 46, Verlag Philipp Von Zabern.

González, A. R. 1998. Cultura la Aguada. Arqueología y diseños. Buenos Aires: Filmediciones Valero.

GonzÁlez, A. R. \& Pérez, J. 2000. Argentina indígena. Vísperas de la Conquista. Buenos aires: Paidós.

Gordillo, I. 1998. Del barro a la figura. Caracterización de la alfarería Aguada de Ambato. En Homenaje a Alberto Rex González. 50 años de aportes al desarrollo y consolidación de la antropología argentina, pp. 285-307. Buenos Aires: Fundación Argentina de Antropología y Facultad de Filosofía y Letras, Universidad de Buenos Aires. 
Gordillo, I. 2007. Eran otros tiempos. Cronología de la integración regional en el NOA. En Sociedades precolombinas surandinas: temporalidad, interacción y dinámica cultural del NOA en el ámbito de los Andes centro-sur, V. Williams, B. Ventura, A. Callegari \& H. Yacobaccio, Eds., pp. 221234. Buenos Aires: Artes Gráficas Buschi.

Gordillo, I. 2009. Dominios y recursos de la imagen: iconografía cerámica del Valle de Ambato. Estudios Atacameños 37: 99-121.

Gordillo, I., Baldini, M. \& Kusch, M. F. 2000. Entre objetos, rocas y cuevas: significados y relaciones entre la iconografía rupestre y mobiliar de Aguada. En Arte en las rocas. Arte rupestre, menhires y piedras de colores en Argentina, M. M. Podestá \& M. de Hoyos, Eds., pp. 101-111. Buenos Aires: Sociedad Argentina de Antropología.

Goretti, M. 2006. Tesoros precolombinos del Noroeste Argentino. Buenos Aires: Fundación Centro de Estudios para Políticas Públicas Aplicadas.

Goretti, M. 2007. Antes de América. Símbolos de culto y poder en las culturas prehispánicas. Buenos Aires: Fundación Centro de Estudios para Políticas Públicas Aplicadas.

Hernández Llosas, M. I. \& Podestá, M. M., 1985. Las composiciones geométricas del arte rupestre de la Quebrada de Humahuaca (Jujuy, Argentina): análisis comparativo. En Estudios en arte rupestre, C. Aldunate, J. Berenguer \& V. Castro, Eds., pp. 109-129. Santiago: Museo Chileno de Arte Precolombino.

Kligmann, D. M. 2009. Procesos de formación de sitios arqueológicos: tres casos de estudio en la puna meridional catamarqueña argentina. Oxford: Archaeopress-British Archaeological Reports International Series 1949.

KLIGmann, D. M. 2015. Archaeological applications of microvertebrate analysis: reconstruction of natural and anthropic processes. Archaeofauna 24: 315-339.

Kligmann, D. M. \& Albino, A. M. 2007. Análisis de los restos óseos de reptiles hallados en una vasija cerámica, Tolombón, Salta. Resúmenes ampliados del XVI Congreso Nacional de Arqueología Argentina, Tomo I, pp. 479-481.

Kligmann, D. M., Albino, A. M. \& Díaz País, E. 2013. Anfisbenas para los dioses: zooarqueología de una ofrenda animal. En De la puna a las sierras: avances y perspectivas en zooarqueología andina, A. Izeta \& G. Mengoni, Eds., pp. 89-120. Oxford: South American Archaeology Series 19, British Archaeological Reports International Series 2564, John \& Erica Hedges.

Kligmann, D. M. \& DíAz PAís, E. 2007. Una primera aproximación a los motivos serpentiformes de la iconografía Aguada del NoA. Intersecciones en Antropología 8: 49-67.

Kligmann, D. M. \& Falchi, M.P. 2018. La imagen de la lagartija en la iconografía prehispánica del Noroeste Argentino I: una propuesta tipológica. Estudios Atacameños 60: 97-131.

Kligmann, D. M., Sesé, C. \& Barbadillo, J. 1999. Análisis tafonómico de la fauna de microvertebrados del Alero 12 (puna meridional catamarqueña argentina) y sus implicancias para el comportamiento humano. Arqueología 9: 9-48.

Korstanje, M. A. 1988. Aguada: contribución al estudio de una iconografía compleja. Tesis de Licenciatura en Historia, Facultad de Filosofía y Letras, Universidad Nacional de Tucumán.

Korstanje, M. A., Lazzari, M., Basile, M., Bugliani, F., Lema, V., Pereyra domingorena, L. \& Quesada, M. (Eds.). 2015. Crónicas materiales precolombinas. Arqueología de los primeros poblados del Noroeste Argentino. Buenos Aires: Sociedad Argentina de Antropología.

Kusch, M. F. 1991. Forma, diseño y figuración en la cerámica pintada y grabada de la Aguada. En El arte rupestre en la arqueología contemporánea, M. M. Podestá, M. I. Hernández Llosas \& S. F. Renard de Coquet, pp. 14-24. Buenos Aires: Salón Gráfico Integral.

LAFone Quevedo, S. 1908. Tipos de alfarería en la región diaguito-calchaquí. Universidad Nacional de la Plata. Buenos Aires: Imprenta de Coni Hermanos.

NASTRI, J. 2005. El simbolismo en la cerámica de las sociedades tardías de los Valles Calchaquíes (siglos XI a XVI). Tesis de Doctorado en Arqueología, Facultad de Filosofía y Letras, Universidad de Buenos Aires.

Palamarczuk, V., Álvarez, A. \& Grimoldi, M. S. 2015. Repensando una época. Aproximación semiótica a los estilos alfareros de inicios del Período Tardío en Yocavil por medio del caso "Lorohuasi". Boletín del Museo Chileno de Arte Precolombino 20 (2): 23-55.

Palermo, M. A. (Ed.). 1984a. Lagartijas y otros saurios I. Buenos Aires: Centro Editor de América Latina.

Palermo, M. A. (Ed.). 1984b. Lagartijas y otros saurios II. Buenos Aires: Centro Editor de América Latina.

Puente, V. \& Quiroga, L. 2006. El tratamiento plástico de la figura humana en las urnas Belén. Elementos para su interpretación. En Memoria del III Congreso de Historia de Catamarca 1, pp. 237-245. Catamarca: Junta de Estudios Históricos de Catamarca, Editorial Científica Universitaria de la Universidad Nacional de Catamarca.

Reynoso, A. \& Pratolongo, G. 2008. Jaguares de nuevo. Consideraciones sobre la temática felínica en la iconografía cerámica del Período Tardío en Yocavil (Noroeste Argentino). Estudios Atacameños 35: 75-96.

Sempé, M. C. 1998. Contacto cultural en el sitio Aguada Orilla Norte. En Homenaje a Alberto Rex González. 50 años de aportes al desarrollo y consolidación de la antropología argentina, pp. 255-283. Buenos Aires: Fundación Argentina de Antropología y Facultad de Filosofía y Letras, Universidad de Buenos Aires.

Sempé, M. C. \& Baldini, M. I. 2002. Contextos temáticos y ordenamientos funerarios en el cementerio Aguada Orilla Norte. Relaciones de la Sociedad Argentina de Antropología Xxvir: 247-269.

Sempé, M. C. \& BALdini, M. I. 2004. Contextos temáticos funerarios de las tumbas aguadas gris grabado del cementerio 
Aguada Orilla Norte, Catamarca. Relaciones de la Sociedad Argentina de Antropología xxix: 275-295.

Serrano, A. 1966. Manual de la cerámica indígena. Córdoba: Assandri.
VILAS, L. 2016. Construcción y deconstrucción del cuerpo. Análisis de figurinas cerámicas del Noroeste Argentino. Actas del XIX Congreso Nacional de Arqueología Argentina, pp. 2379-2381. San Miguel de Tucumán: Facultad de Ciencias Naturales e Instituto Miguel Lillo, Universidad Nacional de Tucumán. 